\title{
SEDIMENT TRANSPORT SIMULATIONS FOR TWO REACHES OF THE COLORADO RIVER, GRAND CANYON, ARIZONA
}

by James P. Bennett

U. S. Geological Survey

Water Resources Investigations Report 93-4034

Prepared in cooperation with the

U. S. BUREAU OF RECLAMATION

Menlo Park, California 


\title{
DEPARTMENT OF THE INTERIOR
}

\author{
BRUCE BABBITT, JR., Secretary
}

\section{U. S. GEOLOGICAL SURVEY}

\author{
Dallas L. Peck, Director
}

For Sale by:

Books and Open-File Reports Section

U.S. Geological Survey

Federal Center, Box 25425

Denver, Colorado 


\section{CONTENTS}

Page

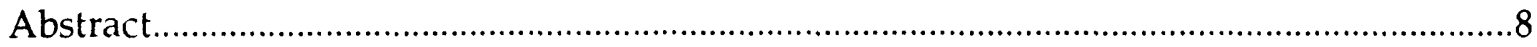

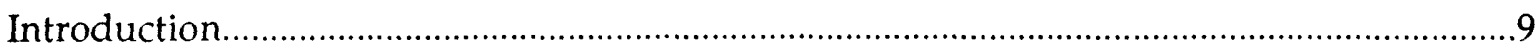

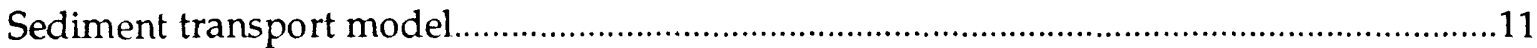

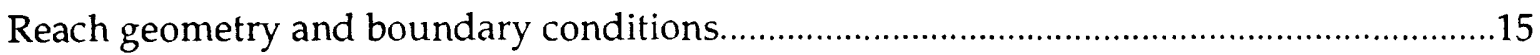

Environmental Impact Statement flow alternatives.........................................................17

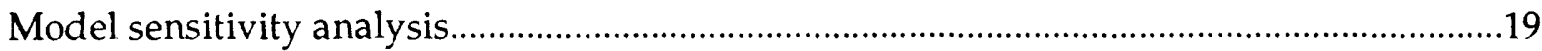

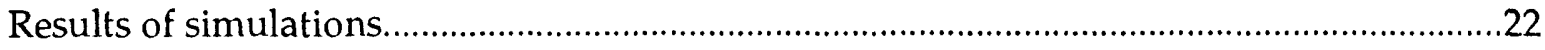

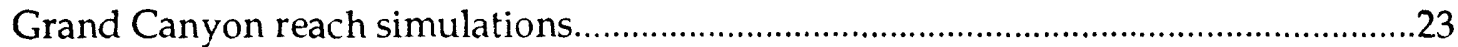

Sand-supply boundary conditions from rating curves.......................................23

Bar-building flows using sand supply from rating curves.................................25

Sand-supply boundary conditions from Paria River..........................................27

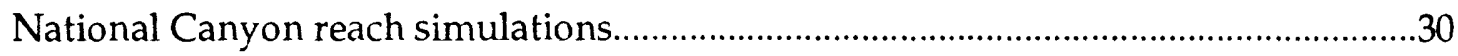

Sand-supply boundary conditions from rating curves.......................................30

Sand-supply boundary conditions from upstream simulation.............................33

Reach response to different boundary conditions.................................................39

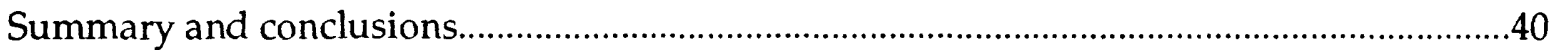

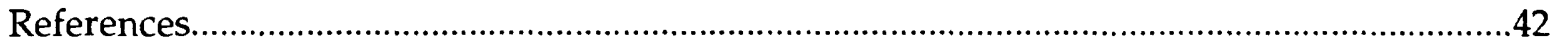




\section{ILLUSTRATIONS}

Page

Figure 1. Location of study reaches and gaging stations

2. Flow and transport model definition sketches: a) cross section, b) eddy storage zone

3. Flow parameters for Glen Canyon Dam Environmental Impact Statement alternatives as of September, 1991. 18

4. Simulated thickness of three bars in Grand Canyon reach using sand supply from rating curves. Bar-building flow is $1,274 \mathrm{~m}^{3} / \mathrm{s}$, following two years of the low fluctuating flow alternative with 8.23 million acre-feet annual flow volumes.

5. Simulated thickness of the two bars in National Canyon reach using sand supply from ratiing curve. Bar-building flow is $1,274 \mathrm{~m}^{3} / \mathrm{s}$, following two years of the low fluctuating flow alternative with 8.23 million acre-feet annual flow volumes 34

6. Simulated thickness of the two bars in National Canyon reach using sand supply routed from Grand Canyon reach simulation. Bar-building flow is $1,274 \mathrm{~m}^{3} / \mathrm{s}$, following two years of the low fluctuating flow alternative with 8.23 million acre-feet annual flow volumes. 


\section{TABLES}

Page

Table 1. Results of sensitivity analysis for National Canyon reach. 20

2. Results of Grand Canyon reach simulations. .24

3. Results of National Canyon reach simulations for rating curve upstream boundary condition.. 31

4. Results of National Canyon reach simulations for upstream boundary condition routed from Grand Canyon reach.. 35 


\section{CONVERSION FACTORS}

Multiply metric unit

meter $(\mathrm{m})$

cubic meter per second $\left(\mathrm{m}^{3} / \mathrm{s}\right)$

kilometer $(\mathrm{km})$

kilogram
3.281

By

To obtain inch-pound unit

35.31

0.6214

2.205 foot

cubic foot per seconc

mile

pound 


\title{
SEDIMENT TRANSPORT SIMULATIONS
}

\section{FOR TWO REACHES OF THE COLORADO RIVER,}

\author{
GRAND CANYON, ARIZONA
}

By

James P. Bennett

\begin{abstract}
A general sand transport model incorporating the specific geometry of two reaches of the Colorado River in Grand Canyon National Park was used to investigate the effects of boundary conditions and flow hydraulics on the sand mass and size composition of deposits in the river channel and eddy storage zones. For equal annual flow volume alternatives, those with greater flow fluctuations generally leave less total sand mass in the simulated reach, but result in higher elevation bar deposits. For alternatives with different annual flow volumes, those with the greater volume also result in less total sand mass in storage in the reach and higher bar deposits. It is difficult to generalize the response of the simulated reaches to bar-building flows, primarily due to the range of possible combinations of boundary condition supply rates and channel transport capacity resulting from the specified hydraulic conditions. For the situations simulated here, the final results are relatively insensitive to the amount of in-reach storage at the inception of the bar-building flow and more sensitive to the rate of supply of sand mass specified by the upstream boundary condition. Even during individual simulations, the rate of bar growth was quite variable and it is not possible to generalize as to predicting the effects of a specific bar-building flow magnitude and duration on final eddy-storage-zone sand surface elevations.
\end{abstract}




\section{INTRODUCTION}

This report is presented as part of the Glen Canyon Environmental Studies (GCES), a cooperative effort of many agencies, including the U.S. Geological Survey (USGS). The U.S. Bureau of Reclamation (USBR) is the lead agency. One of the goals of the effort was to provide information to enable USBR to prepare an Environmental Impact Statement (EIS) of the effects of operation of Glen Canyon Dam on the riparian environmental and cultural resources along the Colorado River in Grand Canyon National Park. This report provides an analysis of the effects of seven EIS flow alternatives on the amount, distribution, and size fractionation of sand and gravel stored in selected reaches of the mainstem Colorado River and its adjacent eddies. The approach taken employs a sediment-transport model which is 'run in' as described below in the section on reach geometry and boundary conditions, using a historical hydrograph and rating curves from the literature to provide an initial amount and distribution of deposits of six size classes of sand and gravel. The model is then run for a specified period (usually 2 years), using hydrographs representative of each of the seven alternatives, and the effects on various characteristics of the deposits are assessed.

Two segments of the Colorado River in Grand Canyon National Park were studied (fig. 1). The first segment, called Grand Canyon reach, extends from river mile 59.3, upstream of the mouth of the Little Colorado River to river mile 87.6, downstream of the USGS Grand Canyon stream gaging station. The upstream 18 miles of this segment is in the reach described by Schmidt and Graf (1990, table 2) as Furnace Flats, a wide (average ratio of top width to depth of 28.6) segment with average slope of 0.0021 and the downstream 10 miles is in the Upper Granite Gorge reach, a narrow (average ratio of top width to depth of 7.0) segment with average slope 0.0023 . This segment was chosen because it is typical of the upstream part of the study area--near the dam so that it was early affected by the removal of the supply of sediment from the upstream Colorado River, but far enough downstream for channel storage and tributary supply to have important effects. It was also chosen because, due to earlier studies, it was possible to characterize well the sediment supply boundary condition.

The second study segment, called National Canyon reach, extends from river mile 164.0 to river mile 166.6, through two rapids and the pool section containing the USGS National Canyon gaging station. This segment is in the Schmidt and Graf (1990) Lower Canyon reach which is intermediate in width with an average ratio of top width to depth of 16.1, and is much less steep than the Grand Canyon reach, at a slope of 0.0013 . The segment was chosen because it is representative of that portion of the study area well downstream from the immediate effects of the dam, because the input sediment boundary condition could be characterized from previous studies, and because it is an area being intensely studied as a part of the ongoing GCES. 


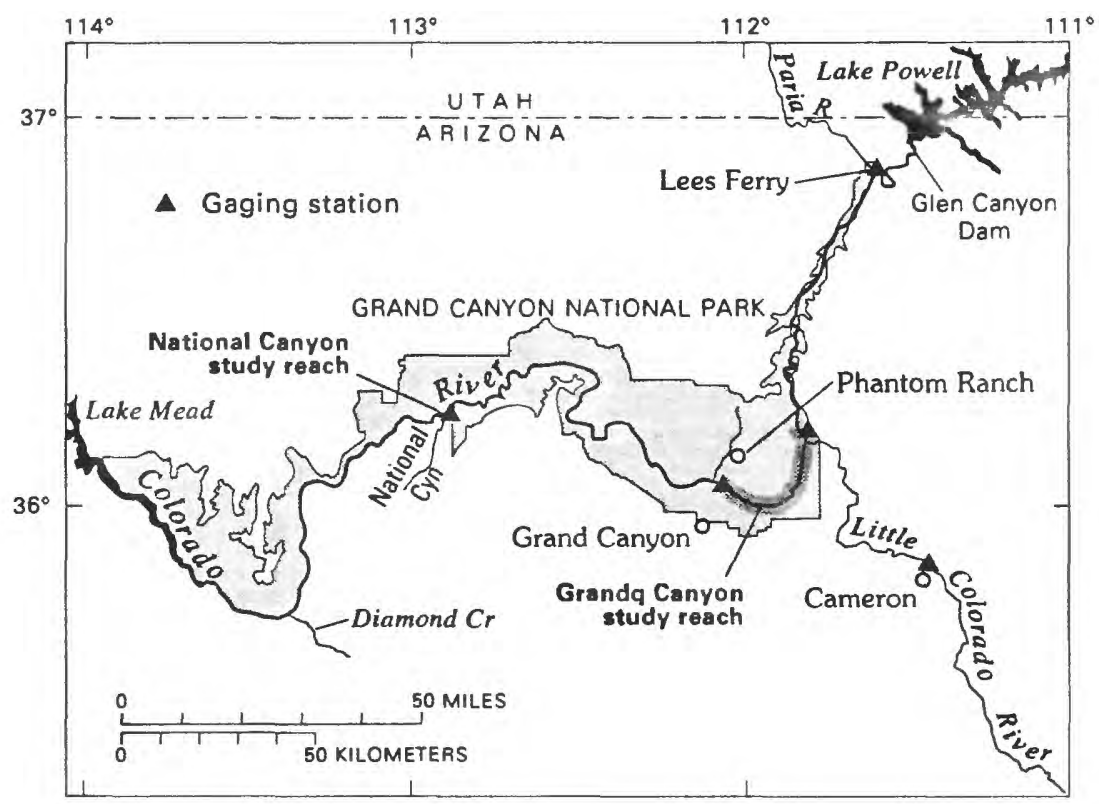

Figure 1. Location of study reaches and gaging stations. 


\section{SEDIMENT TRANSPORT MODEL}

A realistic mathematical model of sand and gravel transport in a stream such as the Colorado River in Grand Canyon requires computation of the (1) hydraulics of the flow, (2) transport capacity by sediment size class, (3) mass, size composition, and geometry of deposits, and (4) subsequent erosion rates, and (5) bulk and surface composition of such of the deposits that have been eroded. Because changes in cross-section geometry caused by erosion or deposition occur relatively slowly in comparison to the rate of change of the discharge hydrograph, and because of the relatively short lengths of the study reaches, it is acceptable to approximate the hydrograph using a sequence of steady flows. This avoids the computational complexity and instabilities inherent in the solution of the unsteady flow equations and allows computation of the flow hydraulics by repeatedly solving a steadystate version of the one-dimensional, gradually varied flow equations (the step-backwater approach described by Henderson, 1969). Because of the steepness of the channel of the Colorado River, and because of the range in discharges encountered, different segments of the reaches of interest may be subjected to supercritical flow at various times. The solution technique employed automatically locates such segments so that no control or critical-flow cross-sections need be specified prior to commencement of the simulation.

The appropriate one of the Yang (1973) sand or Yang (1984) gravel equations is used to determine the transport rates of individual sizes as a function of stream hydraulics. The six sediment size classes considered range in multiples of two from $0.125 \mathrm{~mm}$ thought $4.0 \mathrm{~mm}$, covering the entire range of the sand sizes and fine gravel. Because the two equations do not predict the same transport rate for a size of $2.0 \mathrm{~mm}$ (the boundary between sand and gravel), the transport rate for that size is linearly interpolated between that for $1.0 \mathrm{~mm}$ material from the sand equation and that for $4.0 \mathrm{~mm}$ from the gravel equation.

Transport capacity of the sand-gravel mixture at a particular cross-section is determined by allocating available stream power to sustain the movement of the component sizes according to the rules given below. Stream power is defined as the product, qS, of the water discharge per unit of width, q, and the energy slope, S. (Because the unit-width discharge, q, is used in the definition, the correct term is 'unit stream power'; however, for brevity in what follows the prefix will be omitted.) Stream power is commonly considered to be representative of the work or energy necessary for a stream to transport a given quantity of sediment of a particular size. In determining transport capacity at a cross section, the model first computes the stream power necessary to transport the total masses of all sizes of sediment supplied from the next upstream cross section. If the stream power is not adequate, the finest sizes are transported until the available amount is exhausted; the remaining part of the upstream supply of the size class at which the available power is exceeded is deposited, as are all of the coarser sizes.

Alternatively, if stream power remains after the quantities of all sizes from upstream have been transported, the model computes scour from any deposit existing at the cross section in question. If the stream velocity exceeds the critical value for all sizes present in the deposit, the remaining stream power is allocated such that all sizes are scoured (or transported downstream from the cross section) in proportion to the fraction of the deposit that they constitute. If the stream velocity is less than the critical value for one or more sizes, the remaining stream power is allocated in the same fashion to all sizes in the deposit smaller than the immobile size. When the deposit is sorted such that a thickness of 
immobile sizes equivalent to the diameter of the smallest immobile size is obtained, it is considered to be armored and no additional scour is permitted until the critical velocity for that size is exceeded. The above decision and computation processes are accomplished every time step for every cross section in the simulation reach and are accompanied by an accounting process which keeps track of the masses of the individual size fractions between cross sections, whether or not the bed surface is armored, and of the part of the cross-sectional area occupied by a deposit.

A definition sketch of a cross section is shown in Figure 2a. During simulation, it is assumed that any deposit (sand/gravel) surface is horizontal. Given this assumption, then knowledge of the cross-section geometry and of the amount of mass and the porosity of the deposit permits determination of the elevation of its surface and its width. The cross-section properties so obtained are used in computation of the hydraulics of flow during the next time step. Determination of width based on the assumption of a horizontal deposit surface has the advantage that the active width, $\mathrm{a}_{\mathrm{w}}$, of sand surface need not be specified prior to simulation and may vary in accord with the bedrock channel shape from one time step to the next. Amounts of material in storage in the longitudinal increments are accumulated in terms of the masses in the individual size fractions and all volume, size composition, and scour limitation computations are based on these masses. Thus conservation of mass is strictly adhered to and, over the span of a simulation, the integral of outflow minus inflow mass generally corresponds to the total computed amount of mass in storage to five or six significant figures. Except for the assumption that armoring occurs when a thickness of material equivalent to one diameter of the smallest immobile size is accumulated, the model has no parameters other than those in the sand and gravel transport equations. Other sand and gravel transport equations could have been used but the Yang $(1973,1984)$ equations have been shown to perform well for a wide range of hydraulic conditions (Yang, 1988). Furthermore Yang's relations are particularly convenient for use in the present model because they can be solved analytically for the slope necessary to transport a specified quantity of material of a given size for known hydraulic conditions.

Storage areas to represent eddy zones or backwaters (Figure $2 \mathrm{~b}$ ) can be located at individual cross sections in the model. It is appropriate to do this in areas of flow expansion, usually at cross sections downstream of rapids or other constrictions. These areas are conceptualized as consisting of a plan area, $a_{b}$, available for deposition of sand, at or above an elevation, $z_{b}$, and a length, $l_{s}$, parallel to the stream along which erosion can take place. The sand surface within the storage area is assumed to be horizontal so that if the mass and porosity of the deposit are known, the elevation of the sand surface, $z_{s}$, can be computed. The rate, $x_{m}$, at which sediment mass is transferred into the storage area is then

$$
x_{m}=\frac{k_{1} t_{w} q_{b}\left(z_{w}-z_{s}\right)}{\left(z_{w}-z_{b}\right)}
$$

where $t_{w}$ is the top width of the wetted cross-section, $q_{b}$ is the unit rate of sediment transport past the section in the stream flow, and $\mathrm{z}_{\mathrm{w}}$ is the water surface elevation. Parameter $\mathrm{k}_{1}$, which is dimensionless, may be thought of as the fraction of mainstem mass transport diverted into the storage area at a time when there is no mass in storage in the area, that is, when the ratio of the two terms in parentheses in equation (1) is unity. When $z_{s}$ is greater than $z_{w}$ or when the ratio falls below some critical value, say $0.05, \mathrm{x}_{\mathrm{m}}$ is zero. 
Erosion of mass at a rate $x_{0}$ from the storage area occurs if the stream bottom shear stress, $\tau$, is greater than some critical value, $\tau_{c}$, and if both $z_{w}$ and $z_{s}$ are greater than $z_{b}$. Then

$$
x_{o}=m_{c} k_{2} l_{s}\left(z_{s}-z_{b}\right)\left(\frac{\tau}{\tau_{c}}-1\right)
$$

where $\mathrm{m}_{\mathrm{c}}$ is a constant converting deposit volume to mass and $\mathrm{k}_{2}$ is a characteristic erosion rate, having units length/time. Parameter $k_{2}$ can be thought of as the rate of retreat of the entire face of the sand deposit exposed to the stream at a time when $\tau$ equals two times $\tau_{c}$, because the product $l_{s}\left(z_{s}-z_{b}\right)$ is the area of that face. Parameters $\mathrm{k}_{1}, \mathrm{k}_{2}$, and $\tau_{\mathrm{c}}$ are arbitrary, requiring further laboratory and field observation for independent verification. Limited sensitivity analysis outlining their importance to the current simulation is presented below. 


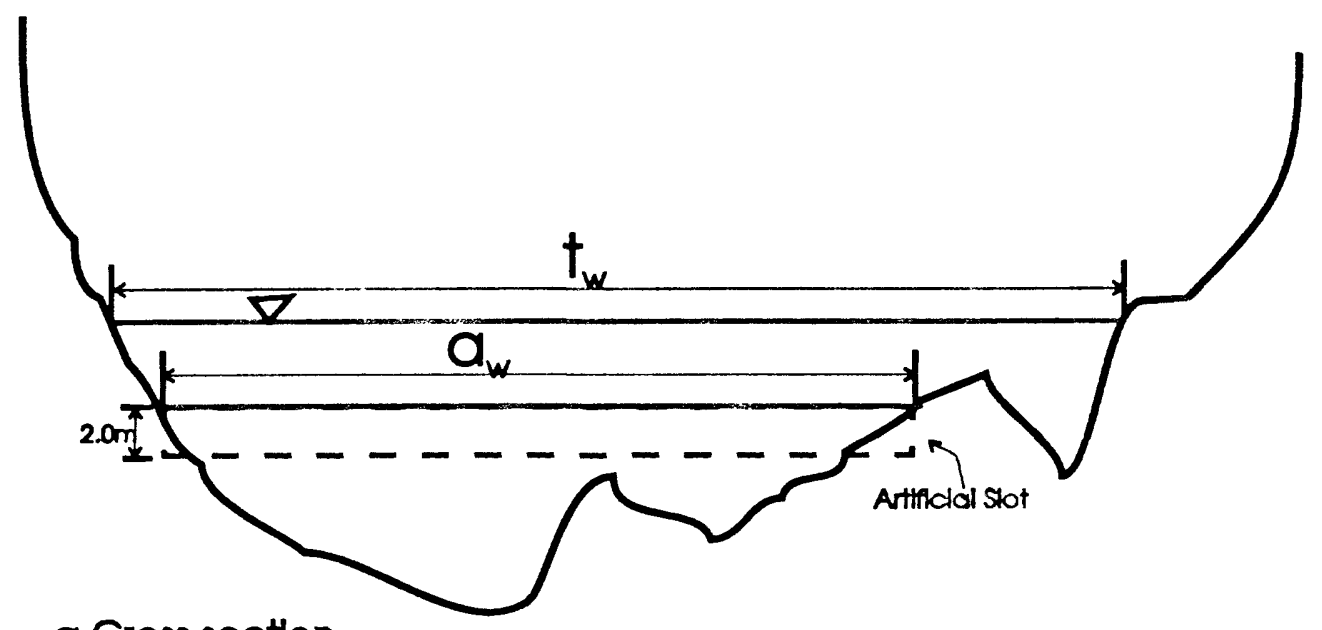

a.Cross section

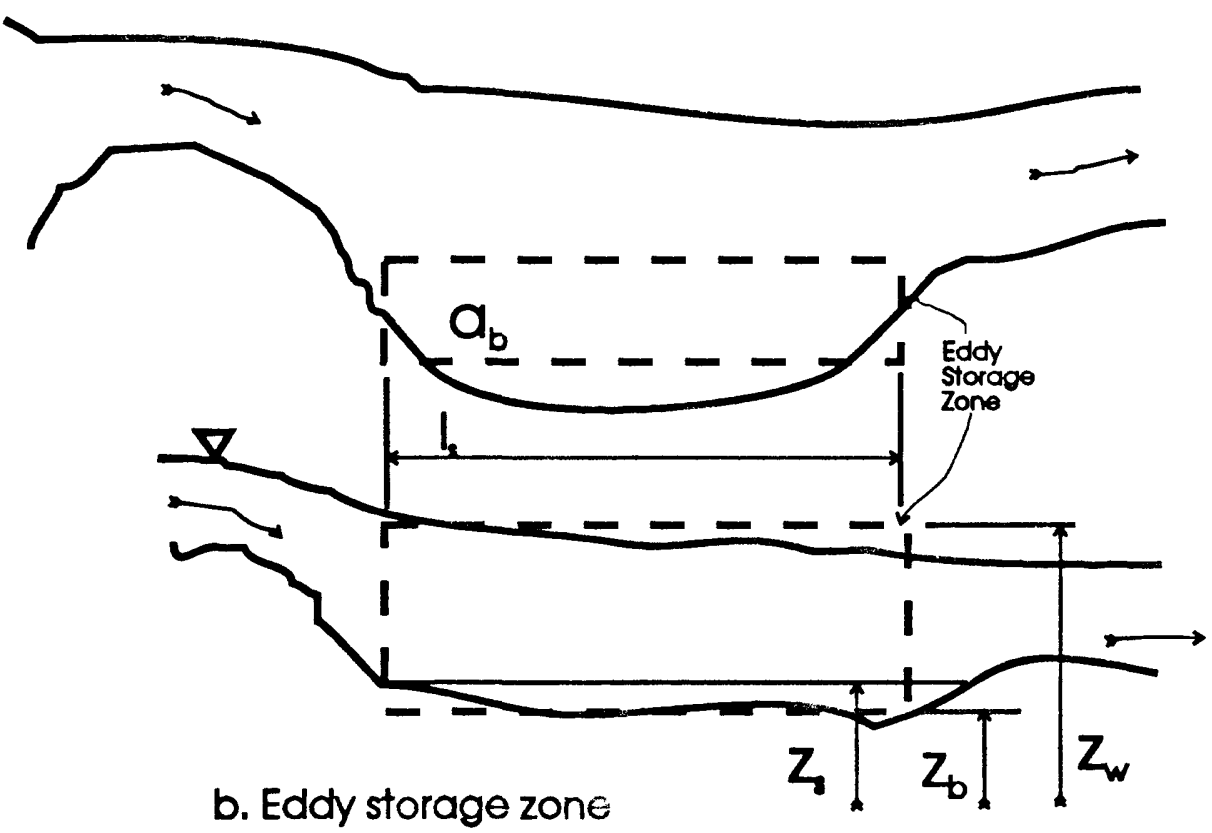

Figure 2. Flow and transport model definition sketches.

$\left[t_{w}\right.$, top width; $a_{w}$, active width; $a_{b}$, storage zone area; $l_{s}$, storage zone length; $z_{b}$, storage zone base elevation; $z_{s}$, storage zone sand surface elevation; $z_{w}$, water surface elevation] 


\section{REACH GEOMETRY AND BOUNDARY CONDITIONS}

The basic cross-section geometry used in this study was obtained from the work of Randle and Pemberton (1987). They dealt with 226 river miles (Lees Ferry to Diamond Creek) and established a consistent vertical datum for the entire study reach, but their longitudinal cross-section spacing is too great for the present investigation. In a typical pool-to-rapids reach, Randle and Pemberton's (1987) cross-section geometry typically consisted of an interpolated cross section at the hydraulic control section (rapids, where echo sounding is virtually impossible) and one or two observed cross sections in the next pool, usually a major fraction of a river mile downstream. This provides a reasonable basis for determining flow characteristics in the riffles but does not provide adequate definition of the bottom geometry or flow characteristics in the more tranquil areas in the pools where storage of sand is expected.

For the Grand Canyon reach, Randle and Pemberton (1987) used 93 cross sections in their analysis and for the National Canyon Reach, they used 9 cross sections. After insertion of additional transitional cross sections, the present simulations used 133 for the Grand Canyon reach and 17 for the National Canyon reach. The dimensions of the additional cross sections were obtained from consideration of the 1983 GCES aerial photos and examination of the original echo sounder profiles used by Randle and Pemberton (1987). Twelve storage zones with a total area of $48,000 \mathrm{~m}^{2}$ (square meters) were inserted as appropriate in the Grand Canyon reach; all but one of these areas are in the Furnace Flats segment, upstream of river mile 77.4. Two storage zones with a total area of $7,000 \mathrm{~m}^{2}$ were used in the National Canyon reach. As mentioned previously, both of these segments were classified as wide reaches by Schmidt and Graf (1990); in the model, the area of storage zones per river mile for these reaches averages $2,500 \mathrm{~m}^{2}$. Although no direct comparison can be made because Schmidt and Graf (1990, table 7) were able to access only the above-water portions of the deposits, the model average compares well with the $2,600 \mathrm{~m}^{2}$ per river mile average for separation plus reattachment deposits they observed for one of two wide reaches during October of 1984 . However this figure is considerably smaller than the one they reported for the other segment; none of the segments they observed are included in the simulation reaches.

Echo soundings provide an accurate measure of channel bottom elevations and an estimate of the type of bottom material deposit can be obtained from grab sampling and inspection of side-scan sonar, but very limited information is available concerning the depths of sand deposits in Grand Canyon. Randle and Pemberton (1987) avoided this problem by arbitrarily specifying the depth of scourable material above bedrock as $20 \mathrm{ft}$. Preliminary model runs using as initial conditions the Randle and Pemberton (1987) bed material and this scour-depth limit proved unsatisfactory because unrealistic scour depths developed at some cross-sections during simulation and because the evolution of the process was exceedingly slow. This made it very difficult to specify reasonable initial conditions for purposes of analyzing the effects of the EIS alternatives. Another approach was adopted in this investigation which involved specifying that the original channel boundary geometry was non-erodible (bedrock) and accommodating the possibility that in some areas the true bedrock bottom could be covered by unknown depths of sand by specifying an artificial trench or slot to be located in the center of the observed cross-section. The width of the slot was set equal to a value corresponding to the part of channel bottom covered by sand as determined by inspection from the Randle and Pemberton (1987) 
bed-material characteristics tables and it was arbitrarily set equal in depth to $2 \mathrm{~m}$ (meters). The effects of variations in these specifications are discussed in the section on sensitivity analysis. In contrast to the Randle and Pemberton (1987) investigation, the 'run-in' period described below was begun with the slot empty of any deposits.

To establish identical initial conditions for comparison of each of the EIS alternatives, simulations were conducted for an arbitrary run-in period. These initial conditions for size composition and depth of the channel bottom deposits at the modeled cross-sections were established in a fashion compatible with both the specified channel geometry and the upstream boundary conditions because the model allowed deposits to accumulate in the channel and eddy storage zones during the run in period. The characteristics of the deposits at the end of the period were saved and used as initial conditions for each of the EIS alternatives evaluated so that each of these simulations would start from the same base. For the selected period, observed daily discharges at the Lees Ferry and Little Colorado River (Cameron, AZ) gages (fig. 1) during water years 1983 through 1986 were used. The primary reason for selecting 1983-86 as the run-in period is that during this time the water discharge and thus the sediment input (as estimated from rating curves) far exceeded that for an average four-year period [the four-year average exceeds $18 \mathrm{maf}$ (million acre-feet) and the post-dam average is $10.5 \mathrm{maf}$ ]. Thus, one is relatively certain that at the end of the period the sand elevations and size compositions throughout the simulation reaches are representative of the input hydrology and rating curves used and not relics of the artificial bare bedrock start up condition. Another important reason for selecting this period is that as the last high runoff period preceding the present investigation, it should provide initial conditions for the study area representative of those at the beginning of the investigation.

For simulation, the upstream boundary conditions required are river discharge and the amount and size distribution of the supplied sediment. As mentioned above, during the run-in period for the Grand Canyon reach, the discharges used were the 1983-1986 daily values observed at the Lees Ferry and Little Colorado River gages, with the discharge from the Little Colorado River being introduced at the appropriate location in the modeled segment. For the National Canyon reach, the sums of the two discharges were used. The upstream boundary condition for sediment supply for the Colorado River upstream of the mouth of the Little Colorado River was obtained using the rating curve of sand load as a function of river discharge from Randle and Pemberton (1987, table 9). The size distribution was determined using Randle and Pemberton (1987, table 10). Similarly, the inputs from the Little Colorado River were obtained using Randle and Pemberton (1987, tables 13 and 14).

To investigate the effects of the boundary condition, a few simulations were conducted in which the only mainstem inputs were those from the Paria River. These inputs were obtained from Randle and Pemberton (1987) in a fashion similar to those from the Little Colorado River. Similarly, two sets of upstream boundary conditions were investigated for the National Canyon reach; the first obtained sand supply and size distribution as for Grand Canyon reach from Randle and Pemberton (1987, tables 9 and 10). The second set was obtained from the output of the model runs for the Grand Canyon reach along with the assumption that the sand load could be transported unchanged in amount or size composition through the intervening 76 river miles from Grand Canyon gage to upstream of National Canyon gage. This assumption is consistent with the findings of Pemberton (1987) who concluded on the basis of the data obtained from earlier studies that the rating curves for the Grand Canyon and National Canyon gages were not statistically different. The results of the investigation of the different boundary conditions are discussed below. 


\section{ENVIRONMENTAL IMPACT STATEMENT FLOW ALTERNATIVES}

The characteristics of the seven EIS flow alternatives investigated were obtained from a document presented to the GCES Cooperating Agencies in September, 1991 (T. J. Randle, USBR, written communication). Since that time, the alternatives have undergone several modifications, none of which could be evaluated in this report. However, it is unlikely that any of these modifications would substantially alter the conclusions reached. For each alternative, the document specifies the mean flow, the permissible minimum and maximum flows, and the allowable rates and amplitudes of fluctuation. Figure 3, abstracted directly from the written communication, describes in part the flow restrictions. For purposes of this analysis, the alternatives have been numbered 1 through 7 from left to right as shown across the chart of the figure. Alternatives 1-3 embody annual, seasonal, and monthly-duration steady flows. Alternative 4 describes a fluctuating flow very similar to that specified by the interim flow regulations adopted in August, 1991. Alternatives 5 and 6 allow greater daily fluctuations and lower limits and 7 is the no action alternative with the largest allowed daily fluctuations and the lowest (minimum flow) limits. In the document and for purposes of this investigation the alternatives are presented in the framework of a water year in which the volume of water discharged at Glen Canyon Dam is 8.23 maf, which is the minimum annual volume required by the Colorado River Compact of 1922. In addition, several simulations were conducted using the post-dam annual average flow volume past the Lees Ferry gage, 10.5 maf.

For the simulations in this investigation, the fluctuating flows are quantified by adding values generated by sine curves of appropriate amplitude to the monthly discharge averages of the existing monthly volume steady flow alternative (alternative 3 ). The sine curves have a period of one day and amplitude selected so as not to violate any of the minimum flow, discharge range, or maximum flow restrictions. Because the sine function has equal oscillations above and below the mean value, instantaneous discharge values during the day are affected, but the daily or monthly volume of discharge is not altered. Although rates of fluctuation were not considered in establishing these descriptions, examination of resulting hourly hydrographs indicates that these restrictions are also met. For the simulations with annual volume different than the base of 8.23 maf, hydrographs are obtained by multiplying the instantaneous values for the base by the ratio of that volume to 8.23 maf. During the 2-year simulations of alternative flows, the observed values from water years 1983 and 1984 for the Little Colorado River were used as the necessary tributary flow boundary condition for the Grand Canyon reach. 


\begin{tabular}{|c|c|c|c|c|c|c|c|}
\hline \multicolumn{8}{|c|}{ ALTERNATIVES IDENTIFIED FOR DETAILED ANALYSIS } \\
\hline & \multicolumn{3}{|c|}{ STEADY FLOW } & \multicolumn{4}{|c|}{ FLUCTUATING FLOW } \\
\hline Alternative no. & 1 & 2 & 3 & 4 & 5 & 6 & 7 \\
\hline & $\begin{array}{l}\text { Year- } \\
\text { round } \\
\text { (YRSF) }\end{array}$ & $\begin{array}{l}\text { Seasonally } \\
\text { adjusted } \\
\text { (SASF) }\end{array}$ & $\begin{array}{c}\text { Existing } \\
\text { monthly } \\
\text { volume } \\
\text { (EMVSF) } \\
\end{array}$ & $\begin{array}{l}\text { Low } \\
\text { (LFF) }\end{array}$ & $\begin{array}{l}\text { Moderate } \\
\text { (MFF) }\end{array}$ & $\begin{array}{l}\text { High } \\
\text { (HFF) }\end{array}$ & $\begin{array}{l}\text { No action } \\
\text { (Existing limits) } \\
\text { (NA) }\end{array}$ \\
\hline $\begin{array}{l}\text { Minimum } \\
\text { flow (cfs) }\end{array}$ & $\begin{array}{l}\text { Yearly } \\
\text { volume } \\
\text { prorated }\end{array}$ & $\begin{array}{l}\text { 7,000 Oct-Dec } \\
11,000 \text { Jan-Mar } \\
20,000 \text { Apr-Jun } \\
\text { 7,000 July-Sep }\end{array}$ & 8,000 & $\begin{array}{l}\text { 5,000 between } \\
\text { 7:00 PM and } \\
\text { 7:00 AM } \\
\text { 8,000 between } \\
\text { 7:00 AM and } \\
\text { 7:00 PM }\end{array}$ & ${ }^{2} 5,000$ & $\begin{array}{l}3,000 \\
5,000 \\
8,000 \\
\text { depending upon } \\
\text { monthly volume, } \\
\text { firm load, and } \\
\text { market conditions }\end{array}$ & $\begin{array}{l}\text { 1,000 Labor Day-- } \\
\text { Easter } \\
\text { 3,000 Easter- } \\
\text { Labor Day }\end{array}$ \\
\hline $\begin{array}{l}\text { Allowable } \\
\text { daily change } \\
\text { in flow } \\
\text { (cfs/day) }\end{array}$ & $\begin{array}{l}2,000 \\
\text { between } \\
\text { days }\end{array}$ & $\begin{array}{l}2,000 \\
\text { between } \\
\text { days }\end{array}$ & $\begin{array}{l}2,000 \\
\text { between } \\
\text { days }\end{array}$ & $\begin{array}{l}{ }^{2} 5,000 \\
6,000 \text { or } \\
8,000\end{array}$ & $\begin{array}{l}+/-45 \% \text { of } \\
\text { mean daily } \\
\text { flow for the } \\
\text { month NTE } \\
12,000^{2}\end{array}$ & $\begin{array}{l}15,000 \text { through } \\
22,000\end{array}$ & $\begin{array}{l}30,500 \text { Labor Day- } \\
\text { Easter } \\
28,500 \text { Easter-- } \\
\text { Labor Day }\end{array}$ \\
\hline $\begin{array}{l}\text { Maximum } \\
\text { releases } \\
\text { (cfs) }^{3}\end{array}$ & $\begin{array}{l}\text { Yearly } \\
\text { volume } \\
\text { prorated }\end{array}$ & $\begin{array}{l}\text { Four seasonal } \\
\text { volumes } \\
\text { prorated }\end{array}$ & $\begin{array}{l}\text { Monthly } \\
\text { volumes } \\
\text { prorated }\end{array}$ & 20,000 & $\begin{array}{l}\text { Based on } \\
\text { monthly } \\
\text { volumes and } \\
\text { allowed daily } \\
\text { changes }\end{array}$ & 31,500 & $\begin{array}{l}31,500 \\
\text { Full power plant } \\
\text { capacity studied } \\
\text { as a subalternative } \\
33,200\end{array}$ \\
\hline $\begin{array}{l}\text { Allowable } \\
\text { ramping } \\
\text { (cfs } / \mathrm{hr} \text { ) }\end{array}$ & None $^{4}$ & None $^{4}$ & None $^{4}$ & $\begin{array}{l}2,500 \text { up } \\
1,500 \text { down }\end{array}$ & $\begin{array}{l}4,000 \text { up } \\
2,500 \text { down }\end{array}$ & $\begin{array}{l}\text { Follow power load } \\
\text { up and } 5,000 \text { or } \\
4,000 \text { down }\end{array}$ & Follow power load ${ }^{5}$ \\
\hline
\end{tabular}

'In high volume release months, the allowable daily change would require higher minimum fiows. For example, the minimum would be $14,000 \mathrm{cts}$ for a monthly release volume of 1.2 maf.

${ }^{2}$ Daily fiuctuation limit of 5,000 cfs for monthly releast, volumes less than 600,000 acre-ft; 6,000 cfs for monthly release volumes of 600,000 to 800,000 acre-feet; and 8,000 cfs for monthly volumes over 800,000 acre-ft.

${ }^{3}$ Maximums represent normal or routine llmits and could be exceeded during high water years to avoid releases above power plant capacity. Some operations would have the following maximum flows that would vary with different monthly volumes. For example:

\begin{tabular}{|c|c|c|c|c|c|}
\hline & $\begin{array}{l}\text { Low water yr. } \\
\text { (8.23 man) }\end{array}$ & $\begin{array}{l}\text { High water yr. } \\
\text { (16 maf) }\end{array}$ & & $\begin{array}{l}\text { Low month } \\
(550,000 \text { maf) }\end{array}$ & $\begin{array}{l}\text { High water yr. } \\
\text { (16 maf) }\end{array}$ \\
\hline $\begin{array}{l}\text { Year-round } \\
\text { Seasonally adjusted }\end{array}$ & 12,000 cts & $22.000 \mathrm{cts}$ & Existing monthly & 9,000 cfs & $\begin{array}{l}20,000 \text { cts } \\
20,000\end{array}$ \\
\hline & & & Moderate fiuctuations & 15,000 & 26,000 \\
\hline
\end{tabular}

${ }^{4}$ Adjustments would allow $+/-1,000$ cfs for power system load changes.

${ }^{5}$ Approximately $8,000 \mathrm{cfs} /$ hour maximum.

Figure 3. Flow parameters for Glen Canyon Dam Environmental Impact Statement alternatives as of September, 1991. Modified from table provided by T. J. Randle (US Bureau of Reclamation, written communication, 1991). 


\section{MODEL SENSITIVITY ANALYSIS}

The scope of this investigation does not permit calibration of the model by comparison to field data. It is therefore especially important to understand the relative effects on the output variables considered of the geometrical assumptions and simplifications, boundary conditions, and the chosen values of the model parameters. Pertinent output variables chosen for consideration include the total mass of sand stored in the simulated reach and the total mass in the eddy storage zones, the depths of sand deposits at key cross sections such as cableways and in eddy zones, and sand deposit size fraction distributions at key locations. All of these variables change with time, and insight into the behavior of the system for a variety of hydrologic forcing conditions can be obtained by monitoring this behavior. In this investigation, however, only the values at the end of a particular simulation period will be presented.

The effects of slight perturbations of a variety of conditions on some pertinent output variables for the National Canyon reach are illustrated in table 1. The simulations used the 1983-86 daily discharges and the rating curve and size distributions obtained as discussed above as boundary conditions. Column 1 of the table describes the condition perturbed, columns 2 and 3 list the amount of mass in $\mathrm{mMg}$ (million megagrams) retained in the entire reach (the system) and in the eddy storage zones. Columns 4 and 5 list the final depth (in meters) of sand deposits at the site of the National Canyon stream gage and in the river mile 164.6 (upstream) eddy storage zone. The next 6 columns give the size distribution of the sand deposit at the stream gage, and the final column lists the total amount of input mass during the simulation period. The first row of the table is presented for comparison to the values in the remaining rows; it lists the values of the output variables when all parameters are set to the basic values discussed above.

Rows 2-5 of the table illustrate the effect of modifying the geometry of the artificial slot in the center of the observed cross-section geometry. For these simulations, the slot was made $1.0 \mathrm{~m}$ shallower, 2.0 $m$ deeper, 25 percent narrower, and 25 percent wider. These changes have the expected effect on the total amount of mass retained, increasing it when the volume of the slot increases and decreasing it when the volume decreases. There is no significant effect on the amount of mass in the storage zones, and very little influence on the absolute elevation of the sand surface at the gaging station section (depth of sand deposit is measured above the bottom of the slot). As expected, there is a slight fining of the sand deposit as the volume of the slot is increased.

The effect of varying the total amount of sand introduced to the system by multiplying the rating curve values by $0.5,0.75$, and 1.25 is illustrated in rows $6-8$ of table 1 . Over the range evaluated, the effect on total mass stored is approximately linear, with the ratio of stored mass to the basic value ranging from 0.51 to 1.18 . There is less effect on mass in the eddy storage zones but it has the same trend as total mass. For the two simulations with input reductions, the sand deposit coarsens and for the other simulation, it fines. This is as would be expected, because the amount of energy available for transport is approximately constant and in the 2 cases with decreased input, it is used in removing proportionally more of the fine material, whereas in the case of increased sand input, more of the fine material must deposit. 
Table 1. Results of model sensitivity analysis for National Canyon reach.

[ $\mathrm{rm}$, river mile; $\mathrm{m}$, meters; $\mathrm{mMg}$, Million megagrams; mm, millimeters]

\begin{tabular}{|c|c|c|c|c|c|c|c|c|c|c|c|c|}
\hline $\begin{array}{l}\text { Row } \\
\text { no. }\end{array}$ & $\begin{array}{l}\text { Situation } \\
\text { investigated }\end{array}$ & \multicolumn{2}{|c|}{$\begin{array}{c}\text { Mass retained } \\
\text { (mMg) }\end{array}$} & \multicolumn{2}{|c|}{$\begin{array}{l}\text { Sand depth } \\
\text { (meters) }\end{array}$} & \multicolumn{6}{|c|}{$\begin{array}{l}\text { Size distribution ot sand } \\
\text { deposit at gaging station } \\
\text { (decimal fraction of cotal) }\end{array}$} & $\begin{array}{c}\text { Input } \\
\text { sand } \\
\text { mass } \\
\text { (mMg) } \\
(12)\end{array}$ \\
\hline 2 & Slot depth $=1.0 \mathrm{~m}$ & 0.499 & 0.054 & 3.69 & 4.84 & 0.000 & 0.211 & 0.570 & 0.210 & 0.008 & 0.001 & .46 \\
\hline 3 & Slot depth $=4.0 \mathrm{~m}$ & 0.740 & 0.053 & 6.35 & 4.76 & 0.000 & 0.328 & 0.486 & 0.132 & 0.052 & 0.001 & 29.46 \\
\hline 4 & Slot width $\times 0.75$ & 0.537 & 0.054 & 4.36 & 4.82 & 0.000 & 0.256 & 0.457 & 0.286 & 0.001 & 0.001 & 29.46 \\
\hline 5 & Slot width $\times 1.25$ & 0.620 & 0.053 & 4.40 & 4.80 & 0.000 & 0.261 & 0.474 & 0.248 & 0.016 & 0.0 & 29.46 \\
\hline 6 & Rating $\times 0.5$ & 0.297 & 0.044 & 3.36 & 3.64 & 0.000 & 0.000 & 0.557 & 0.382 & 0.037 & 0.024 & 14.73 \\
\hline 7 & Rating $\times 0.75$ & 0.454 & 0.050 & 4.19 & 4.36 & 0.000 & 0.091 & 0.567 & 0.296 & 0.023 & 0.024 & 22.09 \\
\hline 8 & Rating $\times 1.25$ & 0.683 & 0.057 & 4.78 & 5.18 & 0.000 & 0.257 & 0.479 & 0.196 & 0.067 & 0.001 & 36.82 \\
\hline 9 & $4 \mathrm{~mm}$ size fract. $=0$ & 0.439 & 0.053 & 3.84 & 4.72 & 0.000 & 0.336 & 0.589 & 0.058 & 0.017 & 0.000 & 29.46 \\
\hline 11 & $\mathrm{k}_{1}$ (eddy in) $\times 2$ & 0.587 & 0.061 & 4.46 & 5.59 & 0.000 & 0.260 & 0.415 & 0.322 & 0.002 & 0.001 & 29.46 \\
\hline 12 & $k_{1}, k_{2}$ (in, out) $\times 2$ & 0.577 & 0.052 & 4.43 & 4.72 & 0.000 & 0.262 & 0.442 & 0.284 & 0.011 & 0.001 & 29.46 \\
\hline & $\mathrm{k}_{2}$ (eddy out) $\times 2$ & 0.569 & 0.043 & 4.43 & 3.73 & 0.000 & 0.259 & 0.459 & 0.267 & 0.014 & 0.001 & 29.46 \\
\hline
\end{tabular}


The effect of altering the size distribution of the incoming sand load is illustrated by rows 9 and 10 of table 1. For these two simulations, all of the input of the $4.0 \mathrm{~mm}$ size fraction and then all of the 4.0 and $2.0 \mathrm{~mm}$ size fractions are eliminated. Considering that these two size fractions together represent at most 0.4 percent of the incoming sand load, their effect on the total deposited mass is appreciable. Because it is mostly the finer material that is transported into the eddy storage zones, there is no effect on the amount of mass in these deposits. As one would expect, the deposit at the gaging station consists of higher proportions of the 0.25 and $0.5 \mathrm{~mm}$ fractions, simply because there is relatively less of the coarser fractions in the input mix.

The effects of varying the parameters in the eddy zone storage model are illustrated by the final 3 rows of table 1 : row 11 , a doubling of the input parameter, $\mathrm{k}_{1}$; row 12 , doubling of both $\mathrm{k}_{1}$ and $\mathrm{k}_{2}$; and row 13 a doubling of the output parameter, $\mathrm{k}_{2}$. The only apparent effect on total mass retained can be traced to the effect on mass retained in eddy storage zones. The mass in the eddy zones is increased with an increase in the input parameter and decreased with the doubling of the output parameter, but these changes are not in proportion with the changes in the parameters. Without further investigation, it is difficult to determine whether the slight decrease in mass in the eddy storage zones shown in row 12 is significant; in any case, the effect of such compensating changes in parameters would be expected to be more on rate of response of the deposits to hydrological forcing than on total mass retained. There is no observable effect of these parameter variations on the size composition of the deposit at the gaging station.

This sensitivity analysis does not indicate a need to modify any of the conditions or parameters investigated for purposes of the simulations conducted to compare the results of the alternative flow patterns. It demonstrates that simulation results can be expected to be moderately sensitive to bedrock geometry, rating-curve and storage-zone parameters, and slightly more sensitive to size composition of the incoming sediment load. If determination of the absolute mass of material in storage in a given reach were of concern, then obtaining the correct measures of these conditions by calibration would be more important than in the present situation where only the relative effects of the various alternative flows are important. 


\section{RESULTS OF SIMULATIONS}

The simulations encompass a range of hydrologic and sediment-load input scenarios for each of the two reaches investigated. Following a run-in period using as input flows the observed daily discharges of water years 1983-1986 with appropriate sediment supply boundary conditions, 2-years each with Lees Ferry discharge volumes of 8.23 maf and 10.5 maf were simulated for each of the EIS alternatives. In addition, for boundary conditions existing at the ends of the 2-year, 8.23 maf periods for the year-round steady flow (YRSF), existing monthly volume steady flow (EMVSF), low fluctuating flow (LFF), and no action (NA) alternatives (figure 3), further simulations were conducted for three 60-day bar-building flows with steady discharges of $934,1,274$, and $1,700 \mathrm{~m}^{3} / \mathrm{s}(33,000$, 45,000, and 60,000 cfs (cubic feet per second)). For the National Canyon reach, simulations were conducted comparing results for sediment supply boundary conditions obtained using the Randle and Pemberton (1987) rating curve with those obtained by applying the output from the Grand Canyon reach directly as input to the downstream reach. 


\section{Grand Canyon Reach Simulations}

The results of the run-in period and the three other groups of simulations for the Grand Canyon reach are summarized in table 2 . The format of table 2 and the remaining tables in this section is similar to that of table 1 , in that the listed depths are absolute distances above some arbitrary datum as of the end of that simulation period, and they integrate the results of previous simulations. For example, the value in row 2, column 5, represents the depth of the deposit at the Grand Canyon gage cross section at the end of the 2-year simulation YRSF, which began with initial conditions specified from the completion of the run-in period of row 1 . However, the masses listed are only representative of what has occurred during that particular simulation period. Therefore, the total mass in the reach for any alternative equals that shown in column 2 plus the amount given in column 2 for the run-in period. Further, for the bar-building simulations, the total amount of mass in the system equals the amount in column 2 , plus the amount for the appropriate 2-year alternative simulation plus that for the run-in period. Thus the total mass in the reach at the end of the simulation of row 16 is $2.36 \mathrm{mMg}(0.91+2.27-0.82)$ : the sums of the values in column 2 , rows 1,2 , and 16 .

Row 1 of table 2 lists a summary of conditions in the Grand Canyon reach at the end of the 4-year runin period. Of the $22.5 \mathrm{mMg}$ sand input during the period, 65 percent is from the mainstem and 35 percent from the Little Colorado River (LCR). Of this amount, $0.91 \mathrm{mMg}$, or 4 percent is retained in the reach at the end of the simulation period and of that amount, 73 percent is in the channel and 27 percent in the eddy storage zones. The amount listed as retained in the eddies is included in the amount retained in the system. At the end of the period, there were no sand deposits at either gaging station cross-section and the deposits at all three of the represented storage zones were less than $2.8 \mathrm{~m}$ thick.

\section{Sand-Supply Boundary Conditions from Rating Curves}

A summary of the simulations for alternatives using 8.23 maf annual flow volume is given in rows 28 of table 2. Because of the differences in flow hydrographs, the input mass of sand varies from 5.63 to $6.07 \mathrm{mMg}$ of which $5.26 \mathrm{mMg}$ is from the Little Colorado River. All of the alternatives result in an increase in mass in storage in the reach and the proportion of mass retained in reference to input is far greater than for the run-in period, ranging from 31 to 47 percent. In addition, the ratio of the final value of mass retained to the initial value ranges from 3.0 for the moderate fluctuating flow (MFF) alternative to 4.1 for the seasonally adjusted steady flow (SASF) alternative. Furthermore, all alternatives result in an increase in mass in the eddy storage zones but the increase is not so dramatic, with the largest ratio of final to initial value being 1.16 for NA alternative. All alternatives result in deposition of sand above the bottom of the cross section at the Grand Canyon gage and the range in depth of the deposit is from 0.2 to $1.7 \mathrm{~m}$ (Column 5, deposit depths in the cross sections are measured relative to the bottom of the slot.). All alternatives result in a decrease in depth of deposit in the storage zone at river mile 63.4 while all but SASF result in slight increases in depth for the two remaining storage zones tabulated. In summary, all of the 8.23 maf annual volume alternative flow simulations result in more than 30 percent of the incoming sand mass being retained in the 26 river mile segment downstream of the Little Colorado River, with as much as a four-fold increase in total mass in storage as compared with the results of the run-in simulation. This dramatic increase in stored mass is accompanied by very little overall change in mass or depth of sand deposits in the eddy storage zones, that is, virtually all of the added mass is retained in the channel. 


\section{Table 2. Results of Grand Canyon reach simulations.}

[Alternatives: YRSF, Year-round steady flow; SASF, Seasonally adjusted steady flow; EMVSF, Existing monthly volume steady flow; LFF, Low fluctuating flow; MFF, Moderate fluctuating flow; HFF, Highly fluctuating flow; NA, No action; mMg, million megagrams; LCR, Above Little Colorado River; Grand, near Grand Canyon; rm, river mile; maf, million acre-feet; cms, cubic meters per second]

\begin{tabular}{|c|c|c|c|c|c|c|c|c|c|c|}
\hline \multirow{5}{*}{$\begin{array}{l}\text { Row } \\
\text { No. }\end{array}$} & \multirow{5}{*}{$\begin{array}{c}\text { Alternative } \\
\text { (1) }\end{array}$} & \multicolumn{2}{|c|}{$\begin{array}{c}\text { Mass Retained } \\
\text { (mMg) }\end{array}$} & \multicolumn{5}{|c|}{$\begin{array}{c}\text { Sand deposit depths } \\
\text { (meters) }\end{array}$} & \multirow{5}{*}{$\begin{array}{l}\text { sim. } \\
\text { time } \\
\text { (days) }\end{array}$} & \multirow{5}{*}{$\begin{array}{l}\text { Infut } \\
\text { Sand } \\
\text { Mass } \\
\text { (mMg) } \\
(10)\end{array}$} \\
\hline & & \multirow[t]{2}{*}{ System } & \multirow[t]{2}{*}{ Eddys } & \multicolumn{2}{|c|}{ Gaging sta. } & \multicolumn{2}{|c|}{ Eddys } & \multirow[b]{2}{*}{$\mathrm{rm84.7}$} & & \\
\hline & & & & LCR & Grand & $\operatorname{sm63.4}$ & $r \operatorname{m68} .5$ & & & \\
\hline & & & & & & & & & & \\
\hline & & (2) & (3) & (4) & (5) & (6) & (7) & (8) & & \\
\hline \multirow{3}{*}{1} & \multirow{3}{*}{ Run-in } & \multicolumn{7}{|c|}{ Rating-Curve Supply } & & \\
\hline & & 0.906 & 0.249 & 0.00 & 0.00 & 2.75 & 2.18 & 1.72 & 1430 & 22.48 \\
\hline & & & Rating & g-Curve $S$ & upply, & $8.23 \mathrm{mat}$ & Annual 1 & 1 Flow & volume & \\
\hline 2 & YRSF & 2.268 & 0.010 & 0.00 & 3.70 & 1.90 & 2.27 & 1.82 & 730 & 5.63 \\
\hline 3 & SASF & 2.803 & 0.001 & 0.00 & 2.99 & 2.06 & 2.10 & 1.64 & 730 & 5.93 \\
\hline 4 & EMVSF & 1.931 & 0.024 & 0.00 & 3.41 & 1.85 & 2.46 & 2.14 & 730 & 5.70 \\
\hline 5 & LFF & 1.881 & 0.026 & 0.00 & 3.30 & 1.76 & 2.46 & 2.19 & 730 & 5.73 \\
\hline 6 & MFF & 1.829 & 0.028 & 0.00 & 2.76 & 1.72 & 2.51 & 2.28 & 730 & 5.84 \\
\hline 7 & NFF & 1.839 & 0.039 & 0.00 & 2.63 & 1.75 & 2.66 & 2.44 & 730 & 6.02 \\
\hline \multirow[t]{2}{*}{8} & NA & 2.191 & 0.040 & 0.00 & 2.16 & 2.52 & 2.64 & 2.31 & 730 & 6.07 \\
\hline & & & \multicolumn{3}{|c|}{ Rating-Curve Supply, } & $10.5 \mathrm{maf}$ & Annual & Flow & volume & \\
\hline 9 & YRSF & 1.667 & 0.016 & 0.00 & 1.85 & 3.13 & 2.26 & 1.76 & 730 & 6.06 \\
\hline 10 & SASF & 2.509 & 0.015 & 0.00 & 1.91 & 3.16 & 2.22 & 1.75 & 730 & 6.72 \\
\hline 11 & EMVSF & 1.333 & 0.032 & 0.00 & 1.12 & 3.19 & 2.47 & 2.07 & 730 & 6.21 \\
\hline 12 & LFF & 1.298 & 0.034 & 0.00 & 0.34 & 3.15 & 2.50 & 2.23 & 730 & 6.29 \\
\hline 13 & MFF & 1.295 & 0.038 & 0.00 & 0.26 & 3.05 & 2.56 & 2.30 & 730 & 6.52 \\
\hline 14 & $\mathrm{HFF}$ & 1.377 & 0.053 & 0.00 & 0.14 & 3.13 & 2.71 & 2.50 & 730 & 6.92 \\
\hline \multirow[t]{2}{*}{15} & NA & 1.338 & 0.056 & 0.00 & 0.00 & 3.13 & 2.73 & 2.55 & 730 & 7.04 \\
\hline & & & Rating & g-Curve s & upply, & $934 \mathrm{cms}$ & $\mathrm{Bar}-\mathrm{Bui}$ & ilding & Elow & \\
\hline 16 & YRSF & -0.822 & 0.042 & 0.00 & 0.11 & 2.05 & 2.74 & 2.63 & 60 & 1.01 \\
\hline 17 & EMVSF & -0.791 & 0.033 & 0.00 & 0.01 & 1.44 & 2.88 & 2.81 & 60 & 1.01 \\
\hline 18 & LFF & -0.817 & 0.032 & 0.00 & 0.24 & 1.36 & 2.87 & 2.84 & 60 & 1.01 \\
\hline 19 & NA & -0.799 & 0.027 & 0.00 & 1.28 & 1.39 & 2.99 & 2.95 & 60 & 1.01 \\
\hline & & & Rating & g-Curve $s$ & upply, & $1,274 \mathrm{~cm}$ & ms Bar-B & Buildins & ig Flow & \\
\hline 20 & YRSF & -1.174 & 0.109 & 0.00 & 0.00 & 2.03 & 3.36 & 3.61 & 60 & 2.19 \\
\hline 21 & EMVSF & -0.933 & 0.095 & 0.00 & 0.00 & 1.70 & 3.45 & 3.62 & 60 & 2.19 \\
\hline 22 & LFF & -1.072 & 0.097 & 0.00 & 0.00 & 1.68 & 3.45 & 3.74 & 60 & 2.19 \\
\hline 23 & NA & -0.864 & 0.085 & 0.00 & 0.00 & 1.68 & 3.52 & 3.69 & 60 & 2.19 \\
\hline & & & Ratino & g-Curve S & upply, & $1,700 \mathrm{~cm}$ & ns $\mathrm{Bar}-\mathrm{B}$ & Building & ig Flow & \\
\hline 24 & YRSF & -1.181 & 0.191 & 0.00 & 0.00 & 2.64 & 4.18 & 4.57 & 60 & 3.94 \\
\hline 25 & EMVSF & -1.099 & 0.178 & 0.00 & 0.00 & 2.29 & 4.23 & 4.67 & 60 & 3.94 \\
\hline 26 & LFF & -1.255 & 0.181 & 0.00 & 0.00 & 2.16 & 4.29 & 4.78 & 60 & 3.94 \\
\hline 27 & NA & -1.095 & 0.169 & 0.00 & 0.00 & 2.28 & 4.31 & 4.78 & 60 & 3.94 \\
\hline & & & Paria & River Sur & pply, & $8.23 \mathrm{maf}$ & Annual & Flow VC & lolume & \\
\hline 28 & Run-in & 0.940 & 0.127 & 0.00 & 0.00 & 0.39 & 1.18 & 0.99 & 1458 & 9.25 \\
\hline 29 & LFF & 2.088 & 0.102 & 2.66 & 3.47 & 2.06 & 2.49 & 2.25 & 730 & 6.07 \\
\hline 30 & LFF & 3.298 & 0.051 & 3.67 & 2.13 & 1.63 & 1.92 & 1.75 & 2920 & 21.91 \\
\hline & & & Paria & River Sul & pply, & $934 \mathrm{cms}$ & Bar-Buil & Lding $F$ & low & \\
\hline 31 & LFF & -1.659 & 0.066 & 0.00 & 1.07 & 2.55 & 2.82 & 2.72 & 50 & 0.06 \\
\hline 32 & LFF & -1.879 & 0.065 & 0.00 & 1.11 & 2.16 & 2.87 & 2.78 & 60 & 0.11 \\
\hline & & & Paria & River Su & pply, & $1,274 \mathrm{cms}$ & $\mathrm{Bar}-\mathrm{Bu}$ & dilding & Flow & \\
\hline 33 & LFF & -0.952 & 0.051 & 0.00 & 0.00 & 2.60 & 2.49 & 2.52 & 12 & 0.02 \\
\hline 34 & LFF & -1.162 & 0.010 & 0.00 & 0.00 & 2.60 & 1.98 & 1.95 & 60 & 0.11 \\
\hline & & & Paria & River Su & pply, & $1,700 \mathrm{cms}$ & s Bar-Bu & dilding & Flow & \\
\hline 35 & LFF & -1.682 & 0.085 & 0.00 & 0.00 & 2.56 & 2.98 & 3.14 & 16 & 0.03 \\
\hline 36 & LFF & -2.633 & 0.054 & 0.00 & 0.00 & 2.09 & 2.92 & 2.96 & 60 & 0.11 \\
\hline
\end{tabular}


The simulations using 10.5 maf annual flow volumes are summarized in rows $9-15$ of table 2 . As compared with the 8.23 maf simulations, the increase in input of sand ranges from 0.43 to $0.97 \mathrm{mMg}$ but the accompanying increase in transport capacity results in less of an increase in mass stored in the reach. Thus the proportion of mass retained ranges from 19 to 37 percent of the input amount and the ratio of final amount retained to initial amount ranges from 2.4 for the MFF to 3.8 for SASF. Because of the greater flow depths and higher transport rates, all of the alternatives result in increased total mass in the eddy storage zones as compared to the 8.23 maf simulations, with the largest ratio of final value to initial value being 1.23 for NA. All but NA result in deposition of sand in the artificial slot at the Grand Canyon gage section, but in no case does its depth rise above the bottom of the channel. All alternatives result in increases in deposit depth for the tabulated storage zones and the increase is greater downstream as compared with upstream with the maximum value ranging from $0.45 \mathrm{~m}$ at river mile 63.4 to $0.83 \mathrm{~m}$ at river mile 84.7 . In summary, despite increased sand input, the alternatives allow less accumulation in the reach with 10.5 maf than with 8.23 maf. Conversely, in each case more sand is retained in the eddy storage zones and all storage zone sand depths are greater than at the beginning of the simulation.

\section{Bar-Building Flows Using Sand Supply from Rating Curves}

Rows 16-27 summarize the results following 60 days of the three levels of bar-building flows for each of four selected alternatives, at the end of the 2 -year simulations using 8.23 maf flow volumes. All of these flows remove mass from the reach and the higher flow rates remove more mass than the lower ones, although none removes more than was accumulated during the previous 2 years of the indicated alternative. For example, the most mass removed was for the $1,700 \mathrm{~m}^{3} / \mathrm{s}$ bar-building flow following LFF (row 26), which removed $1.26 \mathrm{mMg}$, leaving $1.53 \mathrm{mMg}$ in the reach, or 69 percent more than at the start of the 2-year simulation period. In addition, all of the bar-building flows add mass to the eddy storage zones, with the amount of addition proportionally being greater than the increase in discharge, that is, an 82 percent increase in discharge from 934 to $1,700 \mathrm{~m}^{3} / \mathrm{s}$ results in a minimum of 351 percent increase in eddy storage zone mass for YRSF and a maximum increase of 523 percent for NA. As compared with the amount of mass in the eddy storage zones at the end of the 2-year simulations, the $934 \mathrm{~m}^{3} / \mathrm{s}$ flows add relatively little, the ratio of stored mass at the end of the bar-building flow to that at the start ranging from 1.09 for NA to 1.16 for YRSF. Alternatively, for the $1,700 \mathrm{~m}^{3} / \mathrm{s}$ bar -building flow this ratio ranges from 1.65 for EMVSF to 1.74 for YRSF. Only the $934 \mathrm{~m}^{3} / \mathrm{s}$ flow leaves sand on the floor of the artificial slot at the Grand Canyon gage section and for none of the alternatives does the level reach the channel bottom. Despite the overall increase in eddy storage zone mass at all levels of flow, the surface elevation of the sand at the river mile 63.4 deposit decreases for the 934 and 1,274 $\mathrm{m}^{3} / \mathrm{s}$ simulations for all alternatives except YRSF. The amount of this decrease varies from less than $0.1 \mathrm{~m}$ for EMVSF and LFF at $1,274 \mathrm{~m}^{3} / \mathrm{s}$ to more than $1.0 \mathrm{~m}$ for NA at $934 \mathrm{~m}^{3} / \mathrm{s}$. For the other two tabulated storage zones the deposit elevation increases for all discharges and alternatives, ranging from 0.3 to $0.8 \mathrm{~m}$ for $934 \mathrm{~m}^{3} / \mathrm{s}, 0.9$ to $1.8 \mathrm{~m}$ at $1,274 \mathrm{~m}^{3} / \mathrm{s}$, and 1.7 to $2.7 \mathrm{~m}$ at $1,700 \mathrm{~m}^{3} / \mathrm{s}$.

A typical plot of the temporal variation of the storage zone deposit surice elevations is given in figure 4 for LFF at $1,274 \mathrm{~m}^{3} / \mathrm{s}$. This figure shows that the elevation at river mile 63.4 increases for about 10 


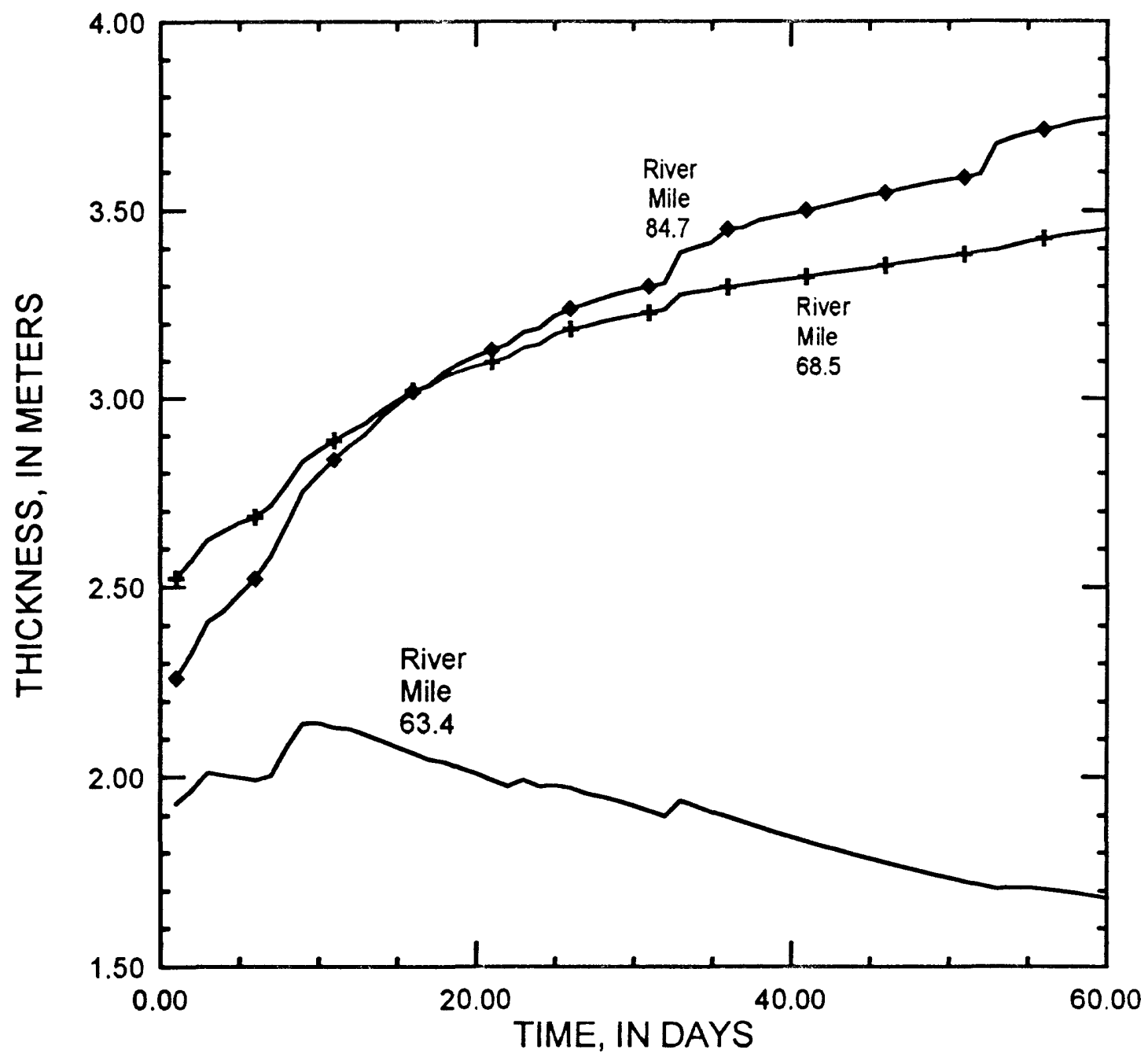

Figure 4. Simulated thickness of three bars in Grand Canyon reach using sand supply from rating curves. Bar-building flow is $1,274 \mathrm{~m}^{3} / \mathrm{s}$, following two years of the low fluctuating flow alternative with 8.23 million acre-feet annual flow volumes. 
days and then gradually declines. This probably indicates that during this time the sand stored in the 2.1 river miles downstream of the Little Colorado River is removed and subsequently the rate of supply from upstream is not sufficient to compensate for the erosion resulting from the increased mainstem flow rate. The figure may also be used to provide insight as to how much bar aggradation might be expected from flow durations of less than 60 days. If the objective is to increase storage zone surface elevations, then durations greater than 10 days are detrimental to the bar at river mile 63.4. During the same time period, the elevation increase at each of the other two tabulated locations achieved 41 percent of the 60-day value, after 20 days it exceeded 61 percent, and after 30 days more than 72 percent. For the stated objective, in this instance, the value of the second 30 days of bar-building flow is questionable. However, the longitudinal and temporal variability in the rate of bar growth illustrated by the figure also indicates that such decisions can be very site-specific and that the optimum decision for one site may be quite detrimental for a nearby location.

For the three bar-building flows investigated, the overall behavior of the simulated reach is similar for all of the four alternatives selected. Each of the bar-building flows removes mass from the reach without exceeding the amount deposited during the preceding two years of 8.23 maf flow volume alternatives and all flows increase the amount of mass in the eddy storage zones. In comparing the different bar-building flows, the amount of this increase is less than 10 percent for the lowest flow but for the other two its growth is proportionately much greater than the increase in the discharge. During one simulation (row 19), the $934 \mathrm{~m}^{3} / \mathrm{s}$ flow resulted in a degradation of $1.1 \mathrm{~m}$ at one location and in increases less than $0.8 \mathrm{~m}$ at others. For only one of the alternatives did the $1,700 \mathrm{~m}^{3} / \mathrm{s}$ simulation result in a decrease in bar elevation and that amounted to about $0.2 \mathrm{~m}$ at river mile 63.4 ; for the two downstream locations, this discharge resulted in increases in elevation exceeding $1.7 \mathrm{~m}$. For the geometrical conditions of all of these simulations, the amount of mass in the storage zones is relatively small, seldom exceeding more than 20 percent of the total in the reach and at the completion of all simulations, being no more than on the order of 1 to 2 percent of the total input mass. For the Grand Canyon reach, the temporal and spatial variation in the rate of bar growth is large and in the instance investigated, more than 70 percent of the resulting bar growth occurred during the first half of the flow period.

\section{Sand-Supply Boundary Conditions from Paria River}

In general, rating curves such as the one used in the simulations discussed earlier are used to make predictions under the assumption that the geomorphology of the stream channel is stable in time. This may not be a good assumption for the Colorado River downstream of Glen Canyon Dam, especially in the reach upstream of the Little Colorado River which must rely primarily on the Paria River for its sand supply. For example, if the four years of run-in discharges are applied to the Randle and Pemberton (1987, table 13) rating curve for the Paria River, a total supply of $1.28 \mathrm{mMg}$ is obtained. This is considerably less than the $14.93 \mathrm{mMg}$ obtained from the rating curve for the mainstem at the gaging station just upstream of the Little Colorado River for the same time period. If both rating curves are correct, the difference must have come from storage somewhere in the intervening reach. If this did happen during 1983-1986, it can not be counted on as a permanent source of supply, and eventually, little more than the long-term average of the Paria River annual load will be available to the reach between the Paria and Little Colorado Rivers. As a conservative alternative to the rating curve, one could assume that the only source of sand to the Grand Canyon reach is the Paria River; that is that 
there is no in-channel storage or any other intermediate source of supply. Thus, rows 28-36 of table 2 are presented to illustrate how a series of simulations such as discussed above might result under such radically different boundary conditions. For this series, only the 1983-1986 daily sand loads for the Paria River are used as the mainstem upstream boundary condition for the Grand Canyon reach. The simulations are conducted only for comparison to others of the low fluctuating flow alternative in the table (rows 5, 12, 18, 22, and 26).

The simulation of row 28 is for run-in purposes and is directly comparable to that of row 1 . Because the Paria River rating curve has a lower yield than that of the mainstem, row 28 shows approximately half as much input sand mass, half as much left in the eddy storage zones, but approximately comparable amounts of total sand in the reach. This occurs because the amount of material transferred to the eddys is proportional to the transport rate in the main channel, whereas the amount of material stored in the channel is largely determined by hydraulics; in the simulation of row 28 , the input mass is much less than for row 1 , but the flows are the same. There are again no deposits at the gaging station sections and the deposit thicknesses are, as would be expected, smaller. Rows 29 and 30 summarize conditions following 2 and 8-year simulations of LFF. Compared with the results of row 5, the 2-year simulation adds slightly more mass to the reach and approximately four times as much to the storage zones; however, ending with $0.046 \mathrm{mMg}$ or 17 percent less mass in the storage zones than for row 5 . The 2-year simulation leaves a $2.7 \mathrm{~m}$ deposit at the upstream gaging station that was not present following the simulation of row 5 and the thickness of the storage zone deposits is quite comparable to those shown. As compared with row 29, the 8-year simulation of row 30 leaves more mass in the reach, but less in the storage zones. The latter condition is due to the fact that storage zone mass is quite sensitive to through-put sand transport and the last 2 years of the simulation period provide only 53 percent of the sand input as for the first two years.

The initial conditions for the bar-building flow simulations of the last 6 rows of table 2 are those at the end of the 8-year LFF. The first row of each pair listed for each of the discharge levels summarizes conditions at the time at which the maximum amount of mass had been added to the eddy storage zones. The elapsed time for this to occur was 50,12 , and 16 days for the $934,1,274$, and $1,700 \mathrm{~m}^{3} / \mathrm{s}$ flows. The second row of each pair shows conditions at the end of the 60-day bar-building flow period, and, except for the $934 \mathrm{~m}^{3} / \mathrm{s}$ case, the amount of mass in the storage zones and the bar thicknesses are appreciably reduced as compared to those at the time of the maximum. In no case does the amount of mass in the storage zones, either at the end of the simulation or at the time of the maximum, approach (the closest being within $0.062 \mathrm{mMg}$ for the $934 \mathrm{~m}^{3} / \mathrm{s}$ flow) that at the end of the comparable simulations in rows 18,22 , or 26 . Furthermore, only in the case of the $934 \mathrm{~m}^{3} / \mathrm{s}$ bar-building flow do the listed deposit thicknesses approach those at the end of the comparable simulations listed earlier in the table. That this occurs has little to do with initial conditions and depends primarily on the fact that for the latter simulations the input mass during the 60 -day period is much lower, being 11,5 , and 3 percent of that for the simulations with the rating-curve boundary condition. In summary, although yielding only slightly more than half as much input mass, the Paria River input boundary conditions result in very similar conditions within the reach at the end of the 4-year run-in period and at the end of the 2-year (and 8-year) LFF simulations. However, only the $934 \mathrm{~m}^{3} / \mathrm{s}$ bar-building flow results in conditions similar to its row 18 analogue and the 1,274 and $1,700 \mathrm{~m}^{3} / \mathrm{s} 60$-day discharges result in 
appreciable reduction in mass in the eddy storage zones as compared to the maximum amount which occurred during the 12th and 16th days. Again, for the assumed reach geometry of all of these simulations, the amount of mass in the eddy storage zones is relatively small, seldom exceeding more than 20 percent of the total in the reach and at the completion of all simulations, being no more than on the order of 1 to 2 percent of the total input mass. 


\section{National Canyon Reach Simulations Sand Supply Boundary Conditions from Rating Curve}

The results of the run-in period and the three other groups of simulations for the National Canyon reach where input sand amounts and size distributions are determined using the rating curve and other information previously described from Randle and Pemberton (1987) are summarized in table 3. As in table 2 , the masses in columns 2 and 3 of the table represent changes during the simulation period indicated and the elevations in columns 4 and 5 incorporate the cumulative changes from the beginning of the run-in period to the end of the simulation. The listed size distributions are also cumulative.

Row lof table 3 lists a summary of conditions in the National Canyon reach at the end of the four-year run-in period. Of the $30.4 \mathrm{mMg}$ sand input during the period, $0.28 \mathrm{mMg}$, less than 1 percent, is retained within the reach and of that amount, 81 percent is in the channel and 19 percent is in the two eddy storage zones. At the end of the run-in period, the deposit at the gaging station section was $2.2 \mathrm{~m}$ above the channel bottom and the one in the eddy storage zone at river mile 164.6 was $4.6 \mathrm{~m}$ thick. The median diameter of the deposit at the gaging station was somewhat less than $0.25 \mathrm{~mm}$ but more than 12 percent of the deposit was coarser than $0.5 \mathrm{~mm}$.

A summary of the alternative simulations for the 8.23 maf annual flow volumes is given in rows $2-8$ of table 3. For these simulations, the input mass of sand varies from 0.8 to $1.95 \mathrm{mMg}$, much less than the corresponding inputs to the Grand Canyon reach. For all flow alternatives, transport capacity exceeds the input amount, resulting in losses of mass both from the eddy storage zones and from the reach. For the reach, the mass loss is greatest for LFF, amounting to 24 percent of the initial value, and least for NA, amounting to 15 percent. For the storage zones, the percentage of mass lost is greatest for YRSF (50 percent) and least for NA (36 percent). The depth of deposit at the gaging station section is reduced for all simulations by an amount ranging from 1.4 to $2.2 \mathrm{~m}$ but not in all cases in proportion to the overall loss in mass from the reach. These discrepancies are explainable by differences in longitudinal distribution of the remaining deposits. Similarly in all cases, the thickness of deposit in the eddy storage zone is reduced, with the loss ranging from 2.2 to $3.0 \mathrm{~m}$ and all of the reductions are proportional to the amount of mass lost. For all simulations, the deposit at the gaging station fines considerably with the median diameter being $0.125 \mathrm{~mm}$ in all cases. Because overall mass is lost from the system, and because this must happen selectively with the finer sizes being removed earliest, this response can not be characteristic of the entire reach. For all alternative flow simulations in this group, the response pattern (loss of mass from the reach) is opposite to that for the Grand Canyon reach. The difference lies simply in the discrepancy between transport capacity of the flow hydrographs and the sand supply rate specified by the rating curve for these same flow conditions. As can be seen by comparison with table 2, for the same hydraulic conditions, the 2-year supply to National Canyon reach for all alternatives, is in excess of $4 \mathrm{mMg}$ less than the supply to Grand Canyon reach. Although it can be seen from table 3 (and from table 4, discussed subsequently) that for these hydraulic conditions the transport capacity of National Canyon reach is less than for the upstream reach, this capacity still exceeds the supply. In summary, all of the 8.23 maf simulations result in loss 
condition.

(Alternatives: YRSF, Year-round steady flow; SASF, Seasonally adjusted steady flcw; EMvSF, Existing monthly volume steady flow; LFF, Low fluctuating flow; MFF, Moderate fluctuating flow; HFF, High:y fluztuating flow; NA, No action; mMg, million megagrams $\mathrm{rm}$, river mile; maf, million acre-feet; cms, oublc meters per second]

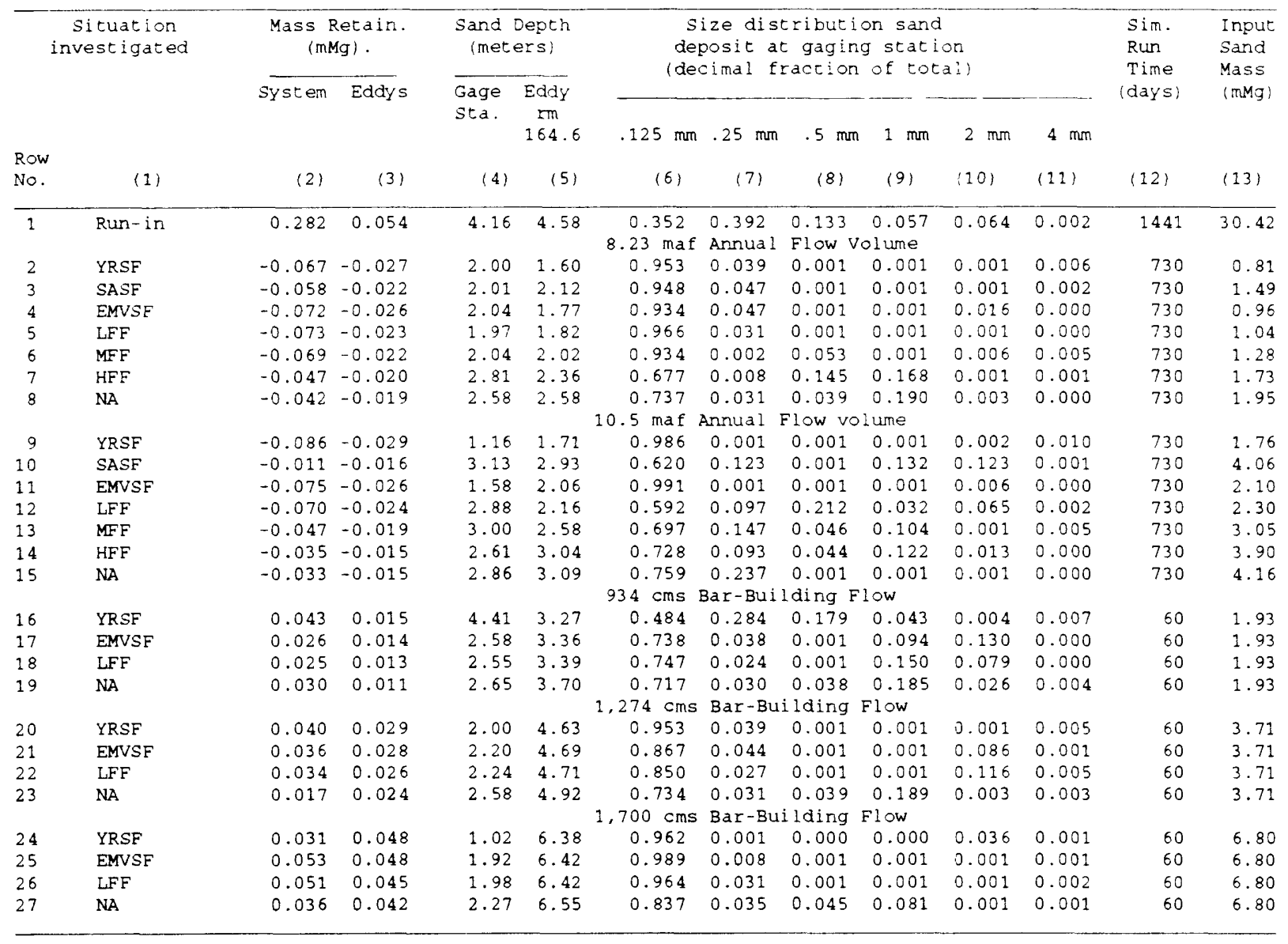


of sand mass in excess of 15 percent of the amount present at the end of the run-in period. The eddy storage zones lose sand at a proportionally greater rate, with the minimum being 36 percent and the minimum reduction in deposit thickness being $2.2 \mathrm{~m}$.

The 10.5 maf annual volume flow alternative simulations are summarized in rows $9-15$ of table 3 . As compared with the 8.23 maf simulations, the increase in input mass ranges from 0.95 to $2.57 \mathrm{mMg}$ but in all cases, both the eddy storage zones and the reach still lose mass. However in two cases for the reach (YRSF and EMVSF), and in two cases for the storage zones (YRSF and LFF), the resulting increase in transport capacity causes a greater loss whereas for the remaining five cases, the loss is less. For the reach, the mass loss is again greatest for LFF, amounting to 30 percent of the initial value, but least for SASF, amounting to 4 percent. For the eddy storage zones, the percentage of mass lost is again greatest for YRSF (54 percent) and again least for NA (27 percent). The depth of deposit at the gaging station section is reduced for all simulations by an amount ranging from 1.1 to $3.0 \mathrm{~m}$. Similarly in all cases, the thickness of deposit in the eddy storage zone is reduced, with the loss ranging from 1.5 to $2.9 \mathrm{~m}$; because of the higher water-surface elevations, higher transport rates, and (in at least two cases) due to longitudinal redistribution of storage, the amount of this loss ranges from 0.1 to $0.8 \mathrm{~m}$ less than for the $8.23 \mathrm{~m}$ simulations. For all simulations, the deposit at the gaging station again fines with the median diameter being $0.125 \mathrm{~mm}$ in all cases; in the two cases where the loss of mass is greater, the shift is greater, in the remaining cases, the shift is less. In summary, with increased sand input, during five of the 10.5 maf simulations less mass is lost than during the 8.23 maf counterparts, whereas for two simulations the opposite is true. Similarly, for five of the simulations less mass is lost from the eddy storage zones and for two, more is lost. However, in all cases the elevation of the sand surface in the eddy storage zone at river mile 164.6 is greater than at the end of the 8.23 maf counterpart, but in no situation does it come closer than $1.5 \mathrm{~m}$ below the level at the end of the run-in period.

Rows 16-27 of table 3 summarize the results following simulations of 60 days of the three levels of bar -building flows for each of four selected alternatives, each of which used 2 years of 8.23 maf annual flow volumes. All of these simulations resulted in additional mass in the reach and in about half the cases, the higher flow rates added more mass; however in no case is there replacement of the amount of mass that was depleted during the previous 2 years of the indicated alternative. Thus, at the end of the bar-building flow the reach always contained less mass than at the end of the run-in period. For example, the most mass added was $0.053 \mathrm{mMg}$ for the highest bar-building flow following EMVSF, leaving $0.263 \mathrm{mMg}$ or 7 percent less than at the start of the 2-year simulation. For only one case (YRSF, for the lowest bar-building flow) does the depth of the deposit at the gaging station section exceed that at the end of the run-in period; for all others it is more than $1.6 \mathrm{~m}$ lower, with the scour generally being greater for the largest bar-building flow. All of the bar-building flows add mass to the eddy storage zones and, as above, the amount of increase is proportionately greater than the increase in discharge. However, none of the $974 \mathrm{~m}^{3} / \mathrm{s}$ bar-building flows replace enough mass for the level of sand in the river mile 164.6 eddy storage zone to reach where it stood at the end of the run-in period, with the closest approach being for NA at $0.9 \mathrm{~m}$ lower. In all cases for the $1,274 \mathrm{~m}^{3} / \mathrm{s}$ bar-building flow the thickness of the deposit in the eddy storage zone equals or exceeds by up to $0.3 \mathrm{~m}$ that at the end of the run-in period while for the $1,700 \mathrm{~m}^{3} / \mathrm{s}$ flow, the range in thickness of the deposit is from 1.8 to $2.0 \mathrm{~m}$ greater. However in two cases (YRSF and NA), the increase in mass in the eddy storage zones is greater than that in the reach so that this results in further loss of mass to the channel deposits. Thus, 
at the end of the highest bar-building flow for YRSF, the amount of mass in the channel deposits is $0.173 \mathrm{mMg}$ (channel storage equals system storage minus eddy storage, or the sum of the values in column 2 , rows 1,2 , and 24 , minus the sum of the values in column 3 , rows 1,2 , and 24 ) or 76 percent of its value at the end of the run-in period.

A typical plot of the temporal variation of the thickness of the eddy storage zone deposit is given in figure 5 for the $1,274 \mathrm{~m}^{3} / \mathrm{s}$ bar-building flow following the 2-year simulation of LFF with 8.23 maf annual flow volume. The figure shows that the deposits at both locations continue to grow throughout the simulation, although the upstream bar increases its thickness at about twice the rate of the downstream one. This occurs despite the fact that the transport rate through the reach is essentially at equilibrium because the depth of water over the top of the upstream bar is twice $(3.6 \mathrm{~m})$ that at the downstream one. The transport rate through the reach is temporally and longitudinally uniform because the sand supply rate is constant (from a rating curve at constant discharge) and because little of the material in transport comes from storage in the reach. Further, because the depth of water over the bars is a significant fraction of the distance above the bottom of the deposit (see equation 1), both graphs are essentially linear. Thus, nearly equal amounts of aggradation will occur during the second 30 days as compared to the first 30 .

In summary, for the three bar-building flows investigated, the general behavior of the simulated reach is similar for all four alternatives investigated. Each of the bar-building flows adds mass to the reach, although not enough to replace that lost during the 2 previous years of simulations of the alternatives using 8.23 maf annual flow volume and all flows increase the amount of mass in the eddy storage zones. However, at the close of the $974 \mathrm{~m}^{3} / \mathrm{s}$ bar-building flow, the surface of the bar at river mile 164.6 remained a minimum of $0.9 \mathrm{~m}$ below the level existing at the end of the run-in period and 60 days of the intermediate flow produced a level only $0.3 \mathrm{~m}$ above it. The bar elevations increase nearly linearly with time and, at the ends of both the intermediate and maximum bar-building flows, both of them were still rapidly increasing in thickness.

\section{Sand Supply Boundary Conditions from Upstream Simulation}

The upstream boundary condition for sand for the set of simulations summarized in table 4 was obtained by introducing the simulated output time series of sand load by size class from the Grand Canyon reach directly as input to the National Canyon reach. The results of the run-in simulation given in row 1 of the table show the total sand supply of $21.6 \mathrm{mMg}$ to be 29 percent less than for the previous set of simulations. However, the amount of sand retained, $0.064 \mathrm{mMg}(0.003$ percent of the input mass), is 77 percent less. Further, in contrast to the previous set of simulations, 73 percent of the mass retained is in the eddy storage zones. These occurrences are a consequence of the difference in size distribution of the input sand, which is also demonstrated by comparing the size composition of the deposits at the gaging station for the two run-in periods; the simulation with sand supplied from the Grand Canyon reach shows much lower proportions of the three coarser sizes. The sensitivity analysis above demonstrates the importance of the size composition of the input load to the results, and the implications of these differences will be discussed in more detail below. Although there is considerable discrepancy between the values of total mass retained for the two simulations, the mass 


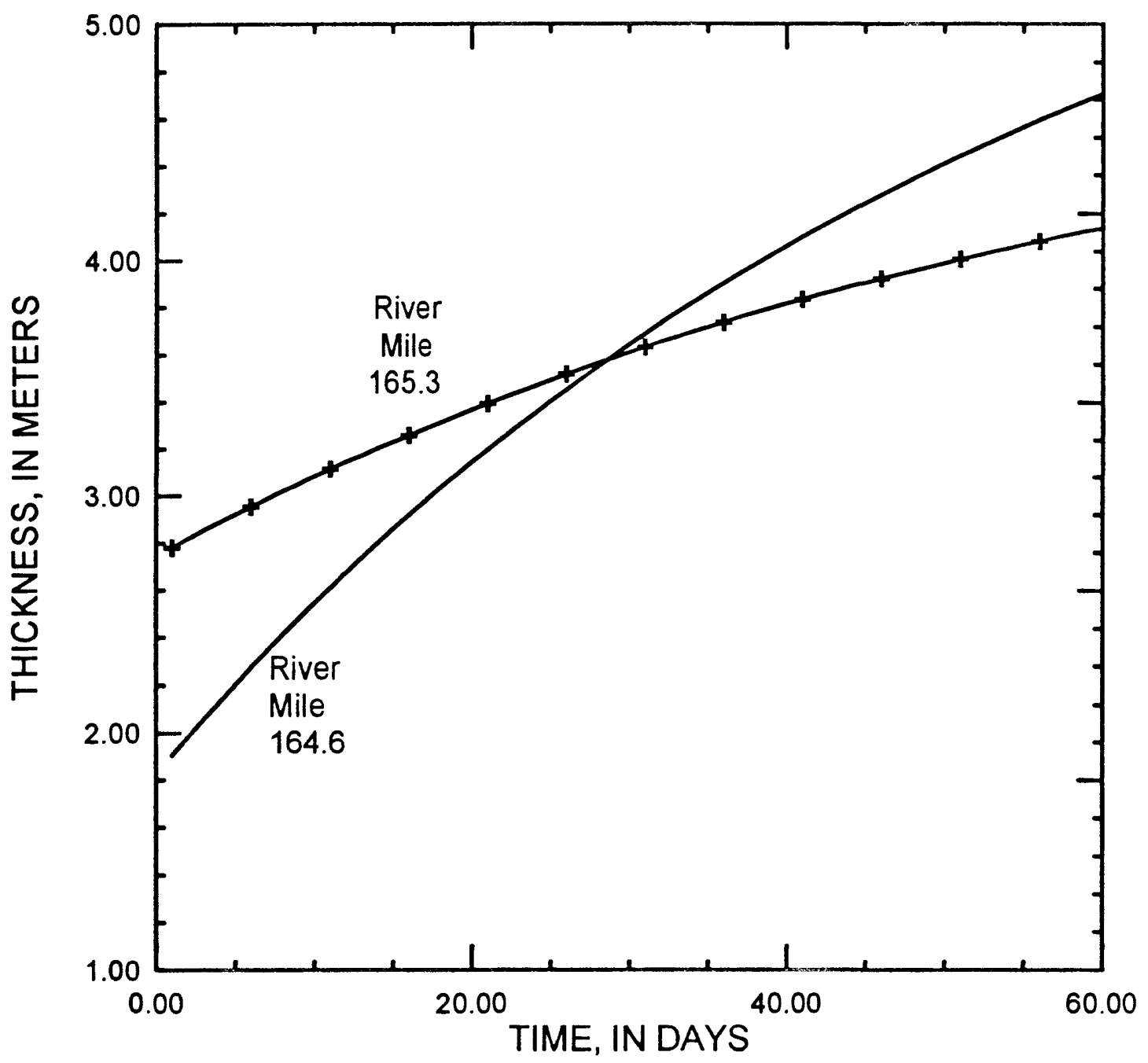

Figure 5. Simulated thickness of the two bars in National Canyon reach using sand supply from ratiing curve. Bar-building flow is $1,274 \mathrm{~m}^{3} / \mathrm{s}$, following two years of the low fluctuating flow alternative with 8.23 million acre-feet annual flow volumes. 
Table 4. Results of National Canyon reach simulations for upstream boundary condition

routed from Grand Canyon reach.

[Alternatives: YRSF, Year-round steady flow; SASF, Seasonally adjusted steady flow; EMVSF, Existing monthly volume steady flow; LFF, Low fluctuating flow; MFF, Moderate fluctuating flow; HFF, Highly fluctiating flow; NA, No action; mMg, million megagrams $\mathrm{rm}$, river mile; maf, million acre-feet; cms, cubic meters per secundi

\begin{tabular}{|c|c|c|c|c|c|c|c|c|c|c|c|c|c|}
\hline \multicolumn{2}{|c|}{$\begin{array}{c}\text { situation } \\
\text { investigated }\end{array}$} & \multicolumn{2}{|c|}{$\begin{array}{c}\text { Mass Retain. } \\
\text { (mMg) }\end{array}$} & \multicolumn{2}{|c|}{$\begin{array}{l}\text { Sand Depth } \\
\text { (meters) }\end{array}$} & \multirow{2}{*}{\multicolumn{6}{|c|}{$\begin{array}{l}\text { Size distribution sand } \\
\text { deposit at gaglng station. } \\
\text { ldecimal fraction of stal: }\end{array}$}} & \multirow{3}{*}{$\begin{array}{l}\text { Sim. } \\
\text { Run } \\
\text { Time } \\
\text { days. }\end{array}$} & \multirow{3}{*}{$\begin{array}{l}\text { input } \\
\text { Sand } \\
\text { Mass } \\
\text { (mMg) }\end{array}$} \\
\hline & & \multirow[t]{2}{*}{ System } & \multirow[t]{2}{*}{ Eddys } & \multirow{2}{*}{$\begin{array}{l}\text { Gage } \\
\text { Sta. }\end{array}$} & \multirow{2}{*}{$\begin{array}{l}\text { Eddy } \\
\mathrm{rm} \\
164.6\end{array}$} & & & & & & & & \\
\hline & & & & & & $.125 \mathrm{~mm}$ & $.25 \mathrm{~mm}$ & $.5 \mathrm{~mm}$ & $1 \mathrm{~mm}$ & $2 \mathrm{~mm}$ & $4 \mathrm{~mm}$ & & \\
\hline $\begin{array}{l}\text { Row } \\
\text { No. }\end{array}$ & (1) & (2) & (3) & (4) & (5) & $(6)$ & (7) & $(8)$ & (9) & $(10)$ & $(11)$ & $(12)$ & (13) \\
\hline 1 & Run-in & 0.064 & 0.046 & 1.02 & 3.83 & $\begin{array}{c}0.284 \\
8.23 \mathrm{maf}\end{array}$ & $\begin{array}{l}0.381 \\
\text { Annual }\end{array}$ & $\begin{array}{l}0.332 \\
\text { Flow Vo }\end{array}$ & $\begin{array}{l}0.002 \\
\text { olume }\end{array}$ & 0.001 & 0.000 & 1430 & 21.57 \\
\hline 2 & YRSF & 0.395 & -0.010 & 4.11 & 2.73 & 0.412 & 0.503 & 0.083 & 0.002 & 0.000 & 0.000 & 730 & 3.36 \\
\hline 3 & SASF & 0.263 & -0.007 & 3.56 & 2.61 & 0.885 & 0.112 & 0.002 & 0.001 & 0.001 & 0.000 & 730 & 3.13 \\
\hline 4 & EMVSF & 0.421 & -0.005 & 4.83 & 3.11 & 0.554 & 0.401 & 0.044 & 0.001 & 0.000 & 0.000 & 730 & 3.76 \\
\hline 5 & LFF & 0.416 & -0.004 & 4.06 & 3.17 & 0.380 & 0.505 & 0.109 & 0.006 & 0.000 & 0.000 & 730 & 3.85 \\
\hline 6 & $\mathrm{MFF}$ & 0.399 & 0.000 & 4.06 & 3.27 & 0.392 & 0.529 & 0.073 & 0.004 & 0.002 & 0.000 & 730 & 4.01 \\
\hline 7 & HFF & 0.402 & 0.007 & 4.05 & 3.45 & 0.367 & 0.505 & 0.126 & 0.001 & 0.001 & 0.000 & 730 & 4.18 \\
\hline 8 & NA & 0.365 & -0.002 & 3.93 & 3.33 & 0.425 & 0.517 & 0.056 & 0.001 & 0.001 & 0.000 & 730 & 3.88 \\
\hline & & & & & & 10.5 maf $A$ & Annual & Flow Vol & lume & & & & \\
\hline 9 & YRSF & 0.322 & -0.007 & 3.79 & 2.90 & 0.504 & 0.409 & 0.081 & 0.006 & 0.001 & 0.000 & 730 & 4.39 \\
\hline 10 & SASF & 0.240 & -0.005 & 3.52 & 2.84 & 0.720 & 0.277 & 0.002 & 0.001 & 0.001 & 0.000 & 730 & 4.22 \\
\hline 11 & EMVSF & 0.337 & -0.002 & 3.81 & 3.36 & 0.596 & 0.126 & 0.273 & 0.005 & 0.000 & 0.000 & 730 & 4.88 \\
\hline 12 & LFF & 0.319 & -0.002 & 3.77 & 3.32 & 0.479 & 0.400 & 0.112 & 0.007 & 0.001 & 0.000 & 730 & 5.00 \\
\hline 13 & MFF & 0.306 & 0.000 & 3.68 & 3.52 & 0.582 & 0.263 & 0.152 & 0.002 & 0.001 & 0.000 & 730 & 5.23 \\
\hline 14 & HFF & 0.293 & 0.002 & 3.64 & 3.69 & 0.633 & 0.269 & 0.091 & 0.005 & 0.001 & 0.000 & 730 & 5.54 \\
\hline 15 & $\mathrm{NA}$ & 0.267 & 0.003 & 3.51 & 3.74 & 0.699 & 0.218 & 0.070 & 0.011 & 0.001 & 0.000 & 730 & 5.70 \\
\hline & & & & & & $934 \mathrm{cms}$ & Bar-Bui & ilding $F$ & Flow & & & & \\
\hline 16 & YRSF & -0.004 & 0.012 & 3.75 & 3.77 & 0.515 & 0.482 & 0.002 & 0.001 & 0.000 & 0.000 & 60 & 1.83 \\
\hline 17 & EMVSF & -0.036 & 0.010 & 1.96 & 3.96 & 0.996 & 0.000 & 0.002 & 0.000 & 0.001 & 0.002 & 60 & 1.80 \\
\hline 18 & LFF & -0.056 & 0.009 & 3.38 & 3.99 & 0.527 & 0.470 & 0.001 & 0.000 & 0.001 & 0.001 & 60 & 1.83 \\
\hline 19 & $\mathrm{NA}$ & -0.015 & 0.008 & 3.66 & 4.10 & 0.396 & 0.600 & 0.000 & 0.002 & 0.001 & 0.000 & 60 & 1.81 \\
\hline & & & & & & $1,274 \mathrm{cms}$ & $=B a r-B L$ & dilding & Flow & & & & \\
\hline 20 & YRSF & -0.079 & 0.024 & 2.98 & 4.77 & 0.771 & 0.223 & 0.001 & 0.001 & 0.001 & 0.002 & 60 & 3.36 \\
\hline 21 & EMVSF & -0.144 & 0.020 & 3.17 & 4.76 & 0.600 & 0.397 & 0.001 & 0.000 & 0.001 & 0.001 & 60 & 3.12 \\
\hline 22 & LFF & -0.158 & 0.020 & 2.72 & 4.90 & 0.999 & 0.000 & 0.000 & 0.000 & 0.000 & 0.001 & 60 & 3.26 \\
\hline 23 & $\mathrm{NA}$ & -0.098 & 0.017 & 3.05 & 4.87 & 0.999 & 0.000 & 0.000 & 0.000 & 0.000 & 0.001 & 60 & 3.06 \\
\hline & & & & & & $1,700 \mathrm{cms}$ & $=B a r-B$ & גilding & Flow & & & & \\
\hline 24 & YRSF & -0.168 & 0.036 & 1.97 & 5.76 & 0.994 & 0.001 & 0.000 & 0.001 & 0.000 & 0.003 & 60 & 5.12 \\
\hline 25 & EMVSF & -0.318 & 0.032 & 0.34 & 5.84 & 0.848 & 0.000 & 0.004 & 0.004 & 0.005 & 0.139 & 60 & 5.04 \\
\hline 25 & LFF & -0.329 & 0.033 & 0.07 & 5.93 & 0.000 & 0.000 & 0.000 & 0.028 & 0.023 & 0.949 & 60 & 5.20 \\
\hline 27 & $\mathrm{NA}$ & -0.307 & 0.029 & 0.05 & 5.93 & 0.000 & 0.000 & 0.024 & 0.000 & 0.030 & 0.947 & 60 & 5.03 \\
\hline
\end{tabular}


retained in the eddy storage zones is only 13 percent less for the run-in period using sand supplied from the Grand Canyon reach. Thus, while the depth of deposit at the gaging station section is $3.1 \mathrm{~m}$ less, the eddy storage-zone deposit is only $0.8 \mathrm{~m}$ thinner.

A summary of the simulations for the alternatives with 8.23 maf annual flow volumes is given in rows 2-8 of table 4. Because of the variable retention ratio in the Grand Canyon reach, the range in supply to the National Canyon reach is greater than shown in table 3, being 3.13 to $4.18 \mathrm{mMg}$ and the scenarios which yield the minimum and maximum are different. The SASF yields the minimum supply and HFF yields the maximum. For all alternatives, the supply exceeds that shown in table 3 and the ratios of the amounts from table 4 to the corresponding ones in table 3 range from 1.99 for NA to 4.15 for YRSF. In contrast to the corresponding simulations of table 3 , all of the alternatives result in an increase in mass in storage in the reach, and the proportion of retention is greater than for the runin period, ranging from 8.4 percent for SASF to 11.2 percent for EMVSF. In addition, the ratio of the final value of mass retained to the initial value ranges from 5.11 for SASF to 7.58 for EMVSF. Five of the alternatives result in loss of mass to the eddy storage zones, with the maximum being 21 percent for YRSF, one results in no change, and HFF results in a 15 percent increase. All alternatives result in deposition of sand above the level of the bottom at the gaging station cross section ( $2 \mathrm{~m}$ above the bottom of the artificial slot) with the maximum depth being $2.8 \mathrm{~m}$ for EMVSF and the minimum being $1.6 \mathrm{~m}$ for SASF. All alternatives result in a decrease in thickness of the eddy storage zone deposit at river mile 164.6, with the maximum being $1.2 \mathrm{~m}$ for SASF and the minimum being $0.4 \mathrm{~m}$ for HFF. As in the simulations of table 3 , the deposit at the gaging station fines but the amount of shift is not so great. In summary, simulations for all of the alternatives using 8.23 maf annual flow volumes result in more than 8 percent of the incoming sand mass being retained in the 2.6 river mile National Canyon reach, with as much as a seven-fold increase of total mass in storage as compared with the run-in simulation. This dramatic increase in stored mass is accompanied by very little change in mass in the eddy storage zones, that is, virtually all of the added mass is retained in the channel.

Simulations for the 10.5 maf annual flow volumes are summarized in rows $9-15$ of table 4 . As compared with the 8.23 maf simulations, the increase in input mass ranges from 1.03 to $1.82 \mathrm{mMg}$, but in all cases the increase in stored mass is less. Thus the proportion of input mass retained ranges from 4.7 to 7.3 percent and the ratio of final amount retained to initial amount ranges from 4.8 for SASF to 6.3 for EMVSF. Four of the alternatives result in decreases in mass in the eddy storage zones, with the maximum amounting to 15 percent for YRSF, whereas three alternatives result in increases, with the maximum increase being 6 percent for NA. All alternatives result in sand deposition above the bottom of the channel at the gaging station section, but in no case does the deposition exceed the amount for the corresponding alternative using 8.23 maf. All alternatives using 10.5 maf result in thicker deposits at the river mile 164.6 eddy storage zone than the comparable one using 8.23 maf, but in no case does the thickness equal or exceed that at the end of the run-in period. Thus, despite increased sand input using 10.5 maf, the alternatives allow less accumulation in the reach than using 8.23 maf, and despite the increased flow ranges, they result in relatively minor increases in the thickness of the eddy storagezone deposit at river mile 164.6. 
Rows 16-27 summarize the results following simulations of 60 days of the three levels of bar-building flows for four selected alternatives each using 2 years of 8.23 maf annual flow volumes. All of these flows remove mass from the reach, and the higher flow rates remove more mass than the lower ones, although none remove more than was accumulated during the previous 2 years of the indicated alternative. For example, the most mass removed was for the highest bar-building flow following LFF which removed $0.32 \mathrm{mMg}$, leaving $0.15 \mathrm{mMg}$ in the reach, or 136 percent more than at the start of the 2-year simulation period. In addition, all of the bar-building flows add mass to the eddy storage zones, with the amount of addition proportionally being greater than the increase in discharge; that is an 82 percent increase in discharge from 934 to $1,700 \mathrm{~m}^{3} / \mathrm{s}$ results in a minimum of 191 percent increase in storage-zone mass for YRSF and a maximum increase of 292 percent for NA. As compared with the amount of mass in the eddy storage zones at the end of the 2-year simulations, the $934 \mathrm{~m}^{3} / \mathrm{s}$ flows add relatively little. The ratio of stored mass at the end of the bar-building flow to that at the start ranged from 1.17 for NA to 1.33 for YRSF. Alternatively, for the $1,700 \mathrm{~m}^{3} / \mathrm{s}$ bar-building flow, this ratio ranged from 1.65 for NA to 1.98 for YRSF. Both the 934 and $1,274 \mathrm{~m}^{3} / \mathrm{s}$ flows leave sand deposited above the channel bottom at the gage section but only YRSF leaves a significant deposit there for the $1,700 \mathrm{~m}^{3} / \mathrm{s}$ bar-building flow. Despite the overall increase in eddy storage-zone mass at all levels of flow, the thickness of the deposit at river mile 164.6 only returns to or slightly exceeds $(0.3 \mathrm{~m})$ its value at the end of the run-in period for the $934 \mathrm{~m}^{3} / \mathrm{s}$ bar-building flow. The thickness exceeds this value by up to $1.1 \mathrm{~m}$ for the intermediate flow and up to $2.1 \mathrm{~m}$ for the highest bar-building flow.

A typical plot of the temporal variation of the surface elevation of the eddy storage zone deposit is given in figure 6 for the $1,274 \mathrm{~m}^{3} / \mathrm{s}$ bar-building flow following 2 years of LFF using 8.23 annual flow volumes. The figure shows that the deposits at both locations continue to grow throughout the simulation but at a decreasing rate as the simulation proceeds. After 20 days of flow the upstream bar has reached 63 percent of the increase in thickness achieved during the entire 60 day period and after 30 days, it has reached 74 percent. Corresponding percentages for the downstream bar are 58 and 70 percent. Thus, more than twice as much aggradation occurs in the first 30 days as compared with the second 30 .

For the three bar-building flows investigated, the overall behavior of the simulated reach is similar for all of the four alternatives selected. Each of the bar-building flows removes mass from the reach for all alternatives without exceeding the amount deposited during the preceding 2 years of 8.23 maf flow volumes, and all flows increase the amount of mass in the eddy storage zones. In comparing the different bar-building flows, the amount of this increase is less than 33 percent for the lowest flow but for the other two the increase is proportionately greater than the increase in the discharge. The $934 \mathrm{~m}^{3} /$ $\mathrm{s}$ flow resulted in deposit thicknesses at river mile 164.6 ranging from equal to $0.3 \mathrm{~m}$ greater than at the end of the run-in period. This thickness was respectively as much as $1.1 \mathrm{~m}$ greater at the end of the $1,274 \mathrm{~m}^{3} / \mathrm{s}$ bar-building flow and $2.1 \mathrm{~m}$ greater following the $1,700 \mathrm{~m}^{3} / \mathrm{s}$ flow. For the instance investigated, more than 70 percent of the resulting bar growth occurred during the first half of the flow period. 


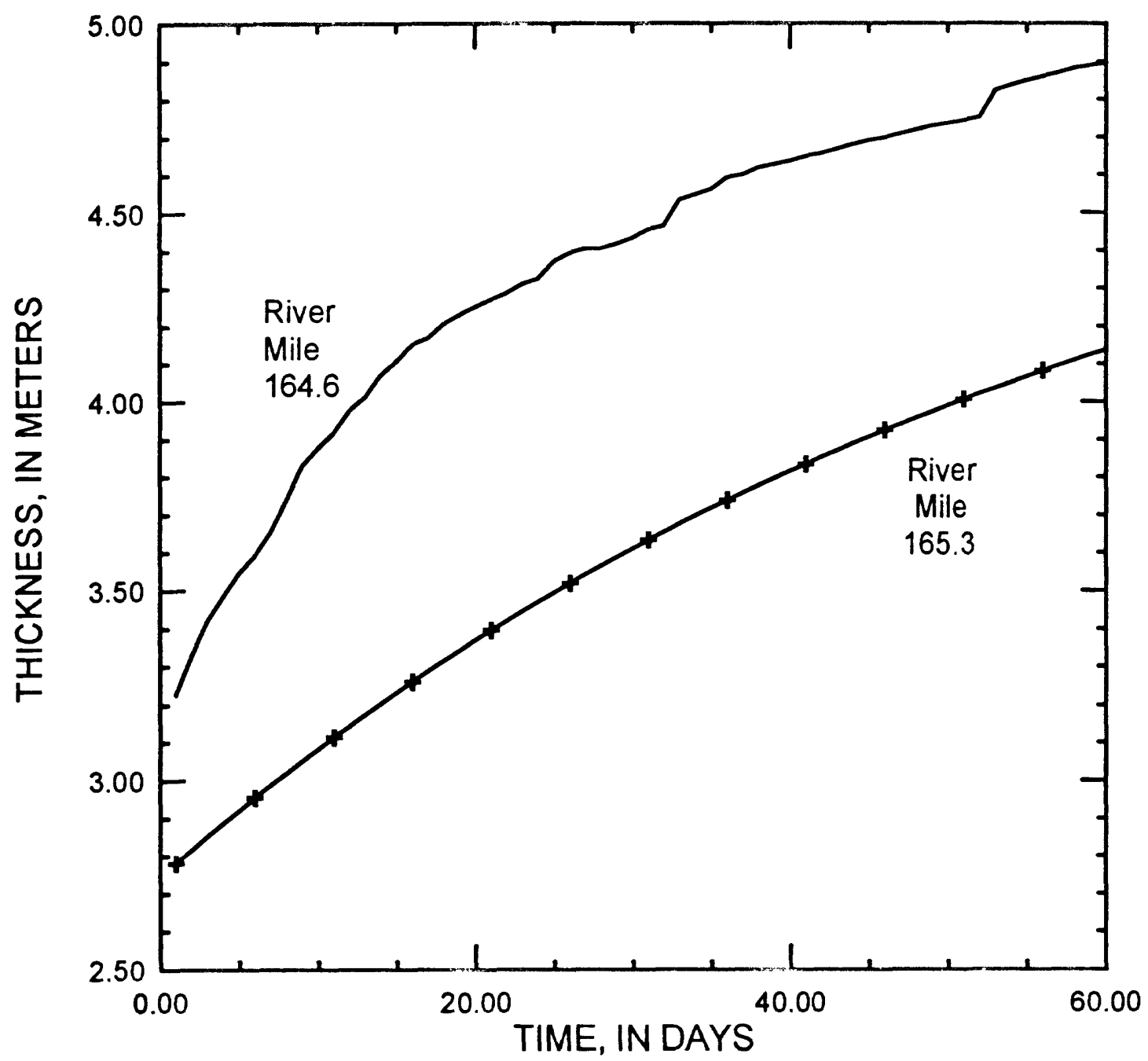

Figure 6. Simulated thickness of the two bars in National Canyon reach using sand supply routed from Grand Canyon reach simulation. Bar-building flow is $1,274 \mathrm{~m}^{3} / \mathrm{s}$, following two years of the low fluctuating flow alternative with 8.23 million acre-feet annual flow volumes. 


\section{Reach Response to Different Boundary Conditions}

For the same geometry and hydraulic conditions, the sets of simulations using different sediment supply boundary conditions, which are summarized in tables 3 and 4 appear to imply radically different behavior. The differences can be explained by considering the size distributions and the ratio of transport capacity to input rate of supply ratio, $\mathrm{R}_{\mathrm{cs}}$, for the two sets of sediment supply boundary conditions. Due to differential deposition of the coarser sizes during transport, the input sand load for the conditions of table 4 is finer than for the conditions of table 3 . Thus, at the end of the run-in period the amount of sand deposited in the reach is much less for the simulations of table 4 than for those of table 3. This would have occurred even if the amount of input for the period equaled the amount shown in table 3 . For all of the alternative flows of the 2 -year simulations, $R_{\mathrm{cs}}$ is greater than unity for the initial conditions of table 3 and the alternatives investigated; hence all simulations show net loss of sand deposits from the reach. Conversely, for the same alternative flows but different initial conditions and supply from upstream, $R_{\mathrm{cs}}$ is less than unity for all of the 2-year simulations of table 4 , and in all cases there is net deposition of sand. At the end of the 2-year 8.23 maf simulations, these different responses have lead to the presence of approximately $0.2 \mathrm{mMg}$ of total deposits in the reach for table 3 and approximately $0.4 \mathrm{mMg}$ for table 4 , a reversal of their positions at the end of the run-in period. At the higher flow rates of the bar-building flows, the $\mathrm{R}_{\mathrm{cs}}$ for table 3 become less than unity and those of table 4 become greater than unity and there is net deposition indicated in table 3 and erosion in table 4. The $R_{c s}$ behave differently as a function of flow rate because in the case of table 3 the supply is a function of the rating curve used, and in the second it is the filtered output of a different rating curve. The 'filtering' is accomplished by the action of differential deposition of the coarser sizes in the Grand Canyon reach.

It is impossible to determine which set of supply conditions is more nearly correct. For the lower discharges, the rating curve clearly supplies much less material and it is possible to question whether it is appropriate for the present use. Pemberton (1987), who derived the original curve, combined all measurements from the gaging stations near Grand Canyon and above National Canyon into a single data set and then fit two curves, one for discharges less than $707 \mathrm{~m}^{3} / \mathrm{s}(25,000 \mathrm{cfs})$, and one for greater discharges. Pemberton's figure 36, which shows the National Canyon data in relation to this curve clearly shows that it underestimates the measurements for flows less than $255 \mathrm{~m}^{3} / \mathrm{s}$ ( $9000 \mathrm{cfs}$ ). If the rating curve were recomputed for only the National Canyon data and perhaps using more than two segments, the agreement between the two approaches might have been better. On the other hand, the procedure using input from the Grand Canyon reach effectively routes material from a high-energy environment (average slope of 0.0023 ) to one of lower energy (average slope of 0.0013 ) without including the effects of the intervening 78 miles of river channel, nor does it provide any mechanism for input of sand from tributary sources. Such mechanisms might reduce the amount of input and coarsen the mixture, causing a shift towards the input boundary conditions of table 3 . If one were to use the five levels of average discharge represented by the individual groups of simulations in each of the tables to derive input rating curves, the one for table 4 would begin at a higher value and have the lesser slope and the two curves would intersect at some value of discharge in the range between 412 and $954 \mathrm{~m}^{3} / \mathrm{s}$. It is in the range between these discharges that one would expect the responses of the two sets of simulations to be the most similar. In fact, comparing the results of the bar-building flows, this appears to happen for a discharge slightly in excess of $974 \mathrm{~m} 3 / \mathrm{s}$. 


\section{SUMMARY AND CONCLUSIONS}

A general sand transport model incorporating the specific geometry of two reaches of the Colorado River in Grand Canyon National Park was used to investigate the effects of boundary conditions and flow hydraulics on the sand mass and size composition of deposits in the river channel and eddy storage zones. Analysis of four sets of simulations leads to several generalizations. First, comparison of alternatives with lower amplitude discharge fluctuations with those with higher amplitudes (for example Year-Round Steady Flow to No Action) shows that Year Round Steady Flow leaves more mass in the reach at the end of the simulation, but that No Action leaves the eddy storage zones at higher elevations. This is accomplished greatly at the expense of storage in the channel. The simulations for the National Canyon reach using rating-curve sediment supply violate the first half of this generalization but adhere to the second half. This is probably due to the fact that for the rating curve input the introduced sand masses for the low amplitude flow alternative scenarios are much less than for the higher amplitude ones. Second, in comparing the 8.23 and 10.5 maf scenarios, the transport capacity generally increases more rapidly than the supply of sand so that the reach is left with less in storage at the end of the 2-year simulation period for the higher annual flow volume scenarios than for the lower ones. In addition, the higher throughput transport rates and water surface elevations of the 10.5 maf alternatives generally leave the eddy storage zone sand-surface elevations at higher levels than for the 8.23 maf counterparts. Again, this is accomplished at the expense of storage in the channel. Third, for a given bar-building flow, bars resulting from simulations following alternatives which permit greater discharge fluctuations tend to end up at higher elevations than those from simulations following ones which permit less fluctuation; that is, bars that start out higher end up higher. Fourth, as compared with the conditions at the end of the run-in period, the $974 \mathrm{~m}^{3} / \mathrm{s}$ bar-building flows are clearly effective only for the downstream two storage zones in the simulations for the Grand Canyon reach. For the other eddy storage zones in the Grand Canyon reach and for those in the National Canyon reach, this level of flow leaves the deposit thickness less than or only slightly above what it was at the end of that initial period. Fifth, the results of this investigation are inconclusive concerning the optimum duration of bar-building flow; in some instances the bars had completed more than 70 percent of their 60-day increase in thickness during 30 days while in others they were still growing strongly at the end of the simulation period. In one case a bar continually decreased in thickness following the 10th day. Sixth, for the reach geometry assumed for all of the above simulations, the amount of mass in the eddy storage zones is relatively small, seldom exceeding more than 30 percent of the total in the reach and at the completion of all simulations, being no more than on the order of 1 to 2 percent of the total input sediment mass.

Finally, the boundary conditions which describe the amount, size composition, and temporal distribution of the input sand mass are very important to determining the end results of the simulations described here. This report has analyzed a possible range of input boundary conditions, but it cannot provide guidance as to the particular ones that might be applicable within the Grand Canyon during the EIS investigation period. This analysis shows that for both reaches in a situation where the ratio of boundary-condition supply rate to transport capacity is large, all 2-year simulations of alternative flows resulted in accumulation of mass in the reach with a reversal of the ratio and consequent loss of mass during the subsequent simulated bar-building flows. However, for the National Canyon reach, where the rating-curve supply rates appear to be anomalously low for the 2-year simulations, the reverse situation occurred. For the National Canyon simulations, wherein the two sets of boundary conditions (supply from rating curves and supply from Grand Canyon reach) provided comparable input sand 
masses, generally comparable eddy storage zone thicknesses resulted. For the Grand Canyon simulations, where the two sets of boundary conditions (supply from rating curves and supply from Paria River) resulted in radically different input sand masses during the bar-building flows, the resulting bar thicknesses were quite different. 


\section{REFERENCES}

Henderson. F. M., 1969, Open Channel Flow, 3rd Edition: New York, Macmillan, 522 p.

Pemberton, E. L., 1987, Sediment data collection and analysis for five stations on the Colorado River from Lees Ferry to Diamond Creek: Glen Canyon Environmental Studies, U. S. Bureau of Reclamation, Salt Lake City, Utah, 158 p.

Randle, T. J., and Pemberton, E. L., 1987, Results and analysis STARS modeling efforts of the Colorado River in Grand Canyon: Glen Canyon Environmental Studies, U. S. Bureau of Reclamation, Salt Lake City, Utah, 182 p.

Schmidt, J. C. and Graf, J. B., 1990, Aggradation and degradation of alluvial sand deposits, 1965 to 1986, Colorado River, Grand Canyon National Park, Arizona: U.S. Geological Survey Professional Paper 1493, 74 p.

Yang, C. T., 1973, Incipient motion and sediment transport: American Society of Civil Engineers, Journal of the Hydraulics Division, v. 99, no. HY10, p. 1679-1704.

1984, Unit stream power equation for gravel: American Society of Civil Engineers, Journal of the Hydraulics Division, v. 110, no. 12, p. 1783-1797.

1988, Sediment transport and unit stream power: in Civil Engineering Practice, Vol. 5, Water resources/environmental, Technomic Publishing Company, Lancaster, PA, P. N. Cheremisinoff, N. P. Cheremisinoff, and S. L. Cheng, eds., p. 265-289. 